\title{
THE IMPACT OF PAVEMENT CONDITION ON THE TRAFFIC ENVIRONMENT POLLUTION
}

\author{
Fathy Mahmoud Mandeel \\ Faculty of Engineering, \\ Zagazig University, EGYPT
}

\begin{abstract}
In addition to its positive impact on the growth and prosperity of the national economy and its importance for satisfying our individual needs for mobility, road transport also has adverse effects: accidents, noise, air pollution, harm to health, crop damage, traffic jams, etc. The outside factors that have adverse impact on the pavement are environment, traffic and pavement maintenance techniques. Pavement maintenance is carried out to reduce the rate of pavement deterioration and subsequently the negative impact of traffic environmental pollution.
\end{abstract}

An effective pavement maintenance program will address pavements, while they are still in good condition and before the onset of serious damage. By applying a cost-effective treatment at the right time, the pavement is restored almost to its original condition. The cumulative effect of systematic, successive maintenance treatments is to postpone costly rehabilitation and reconstruction. Deferring of pavement maintenance leads to more deterioration of pavement, reduction of operating speed and then more pollution to air. The impact on health, welfare and the natural environment are considerable sensitive and having an intangible costs caused by them: These costs are mainly external not covered by the polluters (the motorists) but imposed on everybody. External costs cause a problem to the economy, as they are not included in the market price, which leads to wrong decisions and to a wasting of scarce and vital resources (clean air, silence, clean water, etc.). Motorists behave as if those costs do not exist, since they do not have to pay for them.

The objective of this paper is to quantify the influence of pavement condition status on the environment issue represented by Carbon Monoxide (CO) emission values. To achieve this, the paper consists of four main parts. The first part includes an overview of pavement condition evaluation and the intended performance prediction models. In the second part, a description of the relation between pavement condition and traffic speed will be discussed with the required correlating models. The third part includes quantification of air pollution results from traffic speed reduction within anticipated models. Finally, the effect of pavement condition on traffic environment pollution was identified within an analysis to practical data of different road sections. The results indicate that the environment will; be affected by $0.276,0.176,0.314,0.333,0.279$ and 0.513 ton of $C O$ daily and an accumulated life cycle emissions values; $744.57,466.58,799.66$, $688.88,841.17$ and 972.14 ton for the studied sections respectively depending on variables of pavement condition and traffic volume. The pavement condition has a major impact on the environment than the traffic volume as defined hereinafter. There is a direct proportional of pavement condition with traffic speed and subsequently an inverse relation with the environment emission values, which will affect to the economy and welfare of people.

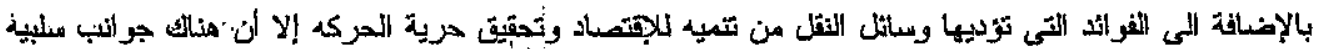

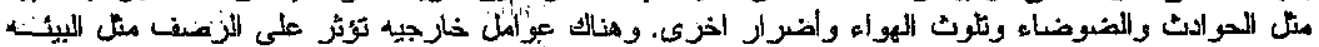

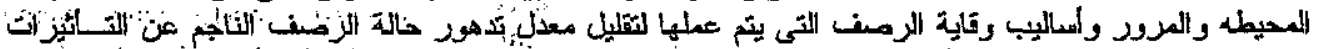

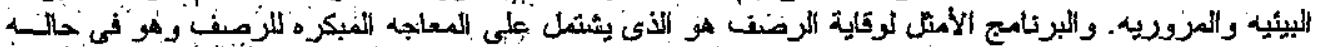

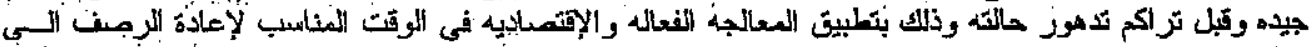

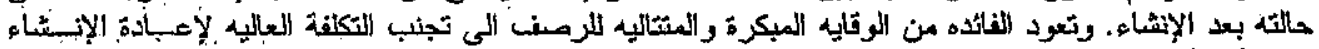

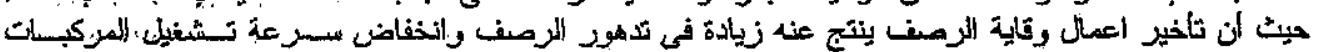

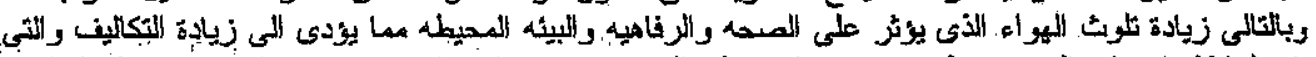

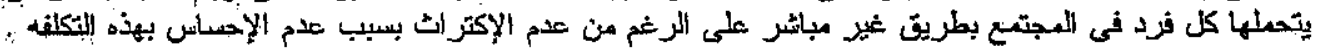




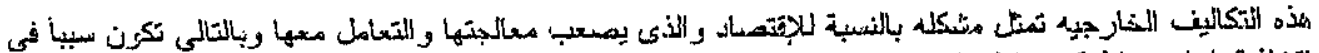

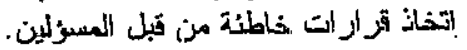

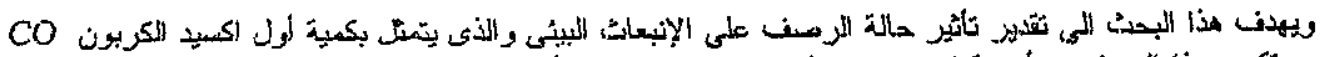

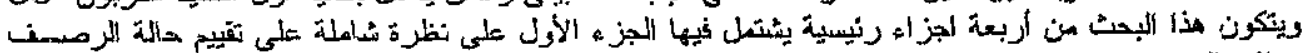

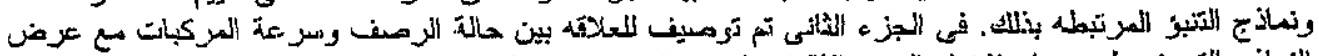

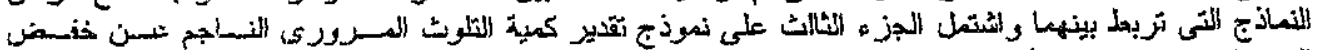

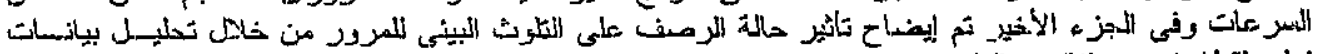

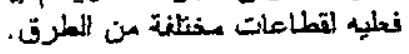

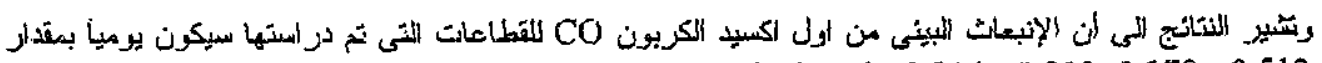

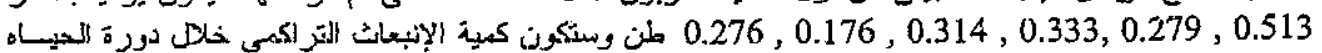

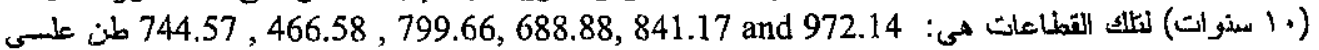

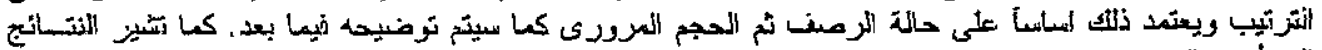

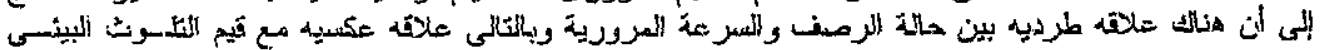

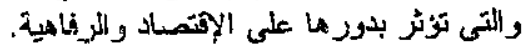

Keywords: Air Pollution; Environment Issue; Traffic; Pavement Maintenance; Performance; Pavement Condition, Emission (Co); Maintenance Techniques; Operating Speed.

\section{INTRODUCTION}

An ideal pavement management systern would yield the best possible value for the available funds; while providing and operating smooth, safe, and economical pavements. The minimum requirements of such a system would include adaptability, efficient operation, practicality, quantitatively, and good feedback information. By including the external costs in the costs of motoring, some trips may produce higher total costs than the total benefits. As a consequence, these trips would have been avoided if all the external costs had to be considered by the driver. In order to stop the wasting of scarce resources, the government has to take action and put a price on clean air and other environmental "products". As a result, negative impacts of road transport have to be paid for by the polluter.

The relationship between air pollution and health established the extent to which different levels of air pollution affect a population's morbidity and mortality. The impacts of traffic-related air pollution were quantified in terms of additional cases of premature death and number and type of additional cases of moroidity. In all countries the air pollution related health effects are far from being negligible. One third of the air poilution is caused by road transport and in the cities the percentage is considerably higher (up to $50 \%$ ). A condition for an environmental and transport policy is knowledge about the negative impacts of road traffic and their monetary quantification. An important part of the extemal traffic-related costs namely the negative impacts of road traffic-related air pollution on human health, need to be evaluated and quantified in monetary terms (I).

\section{EVALUATION OF ROAD-TRAFFIC-RELATED HEALTH IMPACTS AND THEIR MONETARUSATION}

The impacts of traffic related air pollution on human health had to be quantified (number and type of additional cases of morbidity, number of additional cases of prernature death) and valued in monetary terms. This approach is based or a theoretical foundation of welfare economics in considering the individual utility improvement for a reduction in health related risk. It includes the material costs for ambulant or stationary medical treatment, the loss of capacity leading to production and consumption losses as well as intangible costs of pain, fear, suffering and loss in life quality due to air pollution related health effects (2).

As there were no studies giving direct estimates for the health impact of traffic related PM10 (particular matter equivalent or less than $10 \mu \mathrm{m}$ in diameter and a lowest assessed level of $7.5 \mu \mathrm{g} / \mathrm{m}^{3}$ ), the following health outcomes were selected: total mortality based on cohort studies (long-term), respiratory hospital admissions $(3,4)$, cardiovascular hospital admissions and, incidence of chronic bronchitis in adults. Other health may not easily be expressed in monetary values (e.g. lung function decrement, school absentees, physical performance, change in bronchial reactivity), or may be partially included in the above mentioned outcome measures, thus leading to partial double counting of the impact (e.g., premature death due to acute exposure, emergency room visits, respiratory symptoms in adults etc $(5,6)$.

Basically, there are two categories of measures to control motor vehicle emission. One may attack emission problem at the individual level with stringent emission regulations. Secondly, emission control technology improvement followed the 
regulation advances and lowered the emission from tailpipe. The emission control technology can undoubtedly be applied in China. On the other side, seeing the fact that China consumed only $7 \%$ of its total energy consumption each year for transportation and it has more flexibility to develop an energyefficient transport system (7).

\section{METHODOLOGY STATEMENT}

The prime objective of this paper is to quantify the impact of pavement condition on the environmental pollution of traffic. There are three correlated variables; pavement condition, traffic speed and traffic emission. Therefore, the following sections include an explication to; (i) assessment of pavement condition, (ii) traffic speed related to pavement condition, and (iii) air pollution (emission) related to traffic speed. The application of these relations sequentially between pavement condition, traffic speed and traffic emissions leads to quantifying the amount of air pollution for different pavement sections. Consequently, the results were described through actual field data which collected and analyzed as follow;

1- Different road sections ( $6 \mathrm{No}$.) were selected that covers the different levels of road levels, pavement condition and environment conditions.

2- Pavement evaluation was done as a function of pavement distresses; type, quantity and severity levels.

3- Traffic volume and the average running speed were measured for each section.

4- The emission values of traffic were calculated for each section.

5- The results and figures of the above mentioned variables are described hereinafter.

\subsection{Assessment of Pavement Condition}

The purpose of this stage is to evaluate the condition of the pavement sections. This assessment is directly used to determine maintenance needs and consequently the associated lost maintenance benefits per costs as will be explained hereinafter. In this study, pavement evaluation was evaluated in terms of the surface distresses existing at the time of the field evaluation. The Pavement Condition Index (PCI) procedure developed by the United States Army Corps of Engineering (Shahin, and kohn, 1981) was utilized in this study because it deals with the subject of pavement distress identification most comprehensively and is based on a sound statistical technique of pavement sampling\}. In this technique, pavement condition is based on a numerical rating of 0 to 100 , called Pavement Condition Index (PCD). PCI is a combined measure of pavement structural integrity as well as surface operational condition. The technique has been field tested and proven to be a useful device for determining maintenance and rehabilitation (M\&R) needs and priorities for highway pavements. In this technique, the excellent pavement is indicated by a PCI value 85 to 100 , while the failed pavement is indicated by a PCI of 0 to 10 . The intermediate PCI values indicate other intermediate pavement condition ratings. This technique, due to its flexibility of implementation at project as well as network level, has been used in this study. Distress types identification associated with the PCI procedure includes 19 flexible pavement distress types each is classified by three levels of severity: low, medium and high.

The general condition of the pavement is assessed in terms of the Pavement Condition Index (PCI), as follows:

$$
\mathrm{PCI}=\mathrm{C}-\sum_{\mathrm{i}=1}^{\mathrm{m}, 3} \mathrm{i}(\mathrm{Ti}, \mathrm{Sj}, \mathrm{Dij}) \times \mathrm{F}(\mathrm{t}, \mathrm{q})
$$

Where:

$$
\begin{aligned}
\mathrm{PCI}= & \text { Pavement Condition Index }(\mathrm{PCI}) \\
\mathrm{C}= & \text { constant }(\text { usually } 100) \\
\mathrm{I}= & 1, \ldots \mathrm{m}, \text { represents existing distress types. } \\
\mathrm{J}= & 1, . .3, \text { represents distress severity ( low, } \\
& \text { medium and high ) } \\
\mathrm{A}= & \text { weighting factor = function of distress type } \\
& (\mathrm{T}), \text { distress severity (S), and the } \\
& \text { corresponding density (D); } \\
\mathrm{F}= & \text { adjustment factor for multiple distress types. }
\end{aligned}
$$

\section{X.1 Pavement Maintenance Polices}

Polices for pavement rehabilitation and pavement maintenance vary widely from place to place and from time to time. Several factors usually govern these policies: (1) funds available, (2) historical precedent, and (3) political considerations. One or all of these items may be involved with a particular maintenance policy. A maintenance management system (MMS) is a technique or operational methodology for managing or directing and controlling maintenance resources for optimum benefits. It has been pointed out that this involves the following major components (8):

1. An inventory of the physical elements of the system that can be maintained, plus operational and environmental factors.

2. Performance standards that define maintenance procedures, resources and the average accomplishment production rate.

3. Predictions of the workload generated in terms of maintenance accomplishments units by a physical element of the highway.

4. Allocation of available resources through objective budgeting mechanisms based on the specific requirements of the system and policy decisions. 
5. Feedback repoits to monitor and update the system.

6. Planning and scheduling procedures directed toward efficient use of resources.

\subsubsection{Favement Deterioration Rates for Maintenance Techniques}

Behavior of the pavement is the relation, which describes the rate of change of pavement condition over time, under certain level of use (traffic) and subject to specific environmental factors. Simple performance curves procedure was selected to be used, which relates pavement condition index ( $\mathrm{PCr}$ ) to the age of pavement. The general form of this procedure is as follows (9):

$$
C=100-b * X^{-i n}
$$

Where:

$\mathrm{C}=$ Pavement Condition Index (PCI)

$\mathrm{X}=$ Pavement age in months measured from the date of last application of maintenance.

$\mathrm{B}=$ Slope coefficient, 0.0319 for Surface treatment, 0.0158 for thin overlay, 0.0129 for thick overlay, and 0.0104 for reconstruction/ new pavement.

$M=$ Value that controls the degree of curvature of the performance curve $(=1.5)$.

Four different types (most be known) of maintenance techniques considered, these are; 1) Surface treatment, 2) Thin overlay, 3) Thick overlay, and 4) Reconstruction. According to the experiment data of maintenance application, these types of maintenance are applied at different ranges of pavement condition as defined in Table (I).

\subsection{The Relation between Traffic Speed and Pavement Condition}

Traffic speed is directly affected by the condition of the pavement. A field data was collected to detect a relation between traffic speed (all vehicles) and pavement condition. Different sections, from excellent to fair, of pavement condition were used. It was found that pavement condition (PCI) has a statistically significant effect on vehicles speed and the following relation was extracted:

$S=0.496 \times C+28.09, \quad R^{2}=0.999$

(Residual mean square $=$ Residual sum of squares $=$ 0.31957)
Where:

$\mathrm{S}=$ Vehicles speed $(\mathrm{km} / \mathrm{hr})$

$C=$ Pavement condition ( $\mathrm{PCl}$ from 0 to 100 )

\subsection{Prediction of Environment Pollution Values}

Environmental and transport policies are affected negatively by the impacts of road traffic and their monetary quantification. Since, carbon monoxide emissions increases with decreasing the speed of vehicles due to the air-to-fuel ratio supplied to the engine at different speeds. The following relation was extracted to relate Carbon Monoxide (CO) emission rates in $\mathrm{gm} / \mathrm{km}$ to different vehicle speed $(\mathrm{kph})$ values $(\mathrm{I} 0)$.

$$
E=-0.921 \times S+76.268 \mathrm{R}^{2}=0.999
$$

Where:

$\mathrm{E}=$ Emission, $\mathrm{CO} \mathrm{gm} / \mathrm{km} /$ vehicle

$\mathrm{S}=$ Vehicles speed $(\mathrm{km} / \mathrm{hr})$

\section{DATA ANALYSIS AND RESULTS OF THE SELECTED ROAD SECTIONS}

Data was collected for pavement sections that define a relative difference of the considered variables of traffic volume, pavement condition and operating speed. Table (2) defines the values of these variables for different pavement sections in addition to the preferred maintenance type based on the values of Table (1). The calculated current daily and yearly emissions for each section (ton $/ \mathrm{km}$ ) are shown also in Table (2). A life cycle analysis (10 years) was done for each section including the following elements:

1- The current and yearly predicted pavement condition based on the suitable maintenance type for each condition state.

2- The calculated yearly vehicles speed $(\mathrm{km} / \mathrm{hr})$ based on the condition of the pavement.

3- The yearly predicted traffic based on the existing volume and growth factor, which predicted from the history of traffic on each section.

4- The yearly emission was calculated (ton $/ \mathrm{km}$ ) for each section using equation (3) based on the traffic volume and vehicles speed.

5- Subsequently, the yearly accumulated emissions were established.

The analysis results of the above mentioned procedure for each section are shown through Tables 3 to 8. Figures 1 to 5 show the final results of the analysis.

Table (1) Preservation techniques and the suitable condition range for application

\begin{tabular}{|c|c|c|c|c|}
\hline Maintenance Type & Surface treatment & Thin Overlay & Thick Overlay & Reconstruction \\
\hline PCI range & $85-73$ & $73-60$ & $60-47$ & $<47$ \\
\hline
\end{tabular}


Fathy Mahmoud Mandeel, "The Impact of Pavement Condition on the Traffic Environment Pollution"

Table (2) data of pavement sections and the result emission (ton $/ \mathrm{km}$ )

\begin{tabular}{|c|c|c|c|c|c|c|c|}
\hline $\begin{array}{c}\text { Road } \\
\text { (Sec.) }\end{array}$ & $\begin{array}{c}\text { Pav. } \\
\text { Cond. }\end{array}$ & $\begin{array}{c}\text { Operating } \\
\text { Speed }\end{array}$ & $\begin{array}{c}\text { Tr. } \\
\text { Volume }\end{array}$ & G.F. & $\begin{array}{c}\text { Required } \\
\text { Maintenance type }\end{array}$ & $\begin{array}{c}\mathbf{E} \\
\text { daily } \\
\text { (ton/km/day) }\end{array}$ & $\begin{array}{c}\text { E } \\
\text { yearly } \\
\text { (ton/km/year) }\end{array}$ \\
\hline SEC 1 & 57 & 56.4 & 11320 & 10 & Thick Overlay & 0.276 & 100.64 \\
\hline SEC 2 & 82 & 68.8 & 13626 & 4 & Surface Treatment & 0.176 & 64.35 \\
\hline SEC 3 & 40 & 47.9 & 9785 & 11.5 & Reconstruction & 0.314 & 114.73 \\
\hline SEC 4 & 70 & 62.8 & 18070 & 3 & Thin Overlay & 0.333 & 121.49 \\
\hline SEC 5 & 47 & 51.4 & 9645 & 19 & Reconstruction & 0.279 & 101.83 \\
\hline SEC 6 & 67 & 61.3 & 25926 & 1.3 & Thin Overlay & 0.513 & 187.28 \\
\hline
\end{tabular}

Table (3) Section 1; the yearly and accumulated emissions for thick overlay maintenance

\begin{tabular}{|c|c|c|c|c|c|}
\hline Year & PCI & Speed (S) & $\begin{array}{c}\text { Yearly } \\
\text { Traffic }\end{array}$ & $\begin{array}{c}\text { Yearly "E" } \\
\text { 'ton/km' }\end{array}$ & $\begin{array}{c}\text { Accumulated Yearly "E" } \\
\text { 'ton/km' }\end{array}$ \\
\hline 1 & 95.7 & 75.5 & 12452 & 30.41 & 30.41 \\
\hline 2 & 87.8 & 71.6 & 13697 & 51.49 & 81.90 \\
\hline 3 & 77.5 & 66.5 & 15066 & 82.38 & 164.28 \\
\hline 4 & 65.1 & 60.5 & 16573 & 124.13 & 288.41 \\
\hline 5 & 51.7 & 53.7 & 18230 & 178.33 & 466.73 \\
\hline 6 & 99.5 & 77.4 & 20054 & 36.31 & 503.04 \\
\hline 7 & 98.5 & 76.9 & 22060 & 43.56 & 546.60 \\
\hline 8 & 97.2 & 76.3 & 24265 & 53.05 & 599.65 \\
\hline 9 & 95.7 & 75.5 & 26692 & 65.08 & 664.73 \\
\hline 10 & 94.0 & 74.7 & 29361 & 79.84 & 744.57 \\
\hline
\end{tabular}

Table (4) Section 2; the yearly and accumulated emissions for surface treatment maintenance

\begin{tabular}{|c|c|c|c|c|c|}
\hline Year & PCI & Speed (S) & $\begin{array}{c}\text { Yearly } \\
\text { Traffic }\end{array}$ & $\begin{array}{c}\text { Yearly "E" } \\
\text { 'ton } / \mathrm{km}^{\prime}\end{array}$ & $\begin{array}{c}\text { Accumulated Yearly "E" } \\
\text { 'ton/km' }\end{array}$ \\
\hline 1 & 95.7 & 75.5 & 14171 & 34.61 & 34.61 \\
\hline 2 & 87.8 & 71.6 & 14738 & 55.41 & 90.02 \\
\hline 3 & 77.5 & 66.5 & 15327 & 83.79 & 173.81 \\
\hline 4 & 98.7 & 77.0 & 15940 & 30.96 & 204.77 \\
\hline 5 & 96.3 & 75.8 & 16578 & 38.90 & 243.67 \\
\hline 6 & 93.1 & 74.3 & 17241 & 49.48 & 293.16 \\
\hline 7 & 98.7 & 77.0 & 17931 & 34.83 & 327.98 \\
\hline 8 & 96.3 & 75.8 & 18648 & 43.76 & 371.74 \\
\hline 9 & 93.1 & 74.3 & 19394 & 55.66 & 427.40 \\
\hline 10 & 98.7 & 77.0 & 20170 & 39.18 & 466.58 \\
\hline
\end{tabular}

Table (5) Section 3; the yearly and accumulated emissions for reconstruction

\begin{tabular}{|c|c|c|c|c|c|}
\hline Year & PCI & Speed (S) & $\begin{array}{c}\text { Yearly } \\
\text { Traffic }\end{array}$ & $\begin{array}{c}\text { Yearly "E" } \\
\text { 'ton/km' }\end{array}$ & $\begin{array}{c}\text { Accumulated Yearly "E" } \\
\text { 'ton/km' }\end{array}$ \\
\hline 1 & 95.7 & 75.55 & 10910 & 26.64 & 26.64 \\
\hline 2 & 87.8 & 71.63 & 11347 & 42.66 & 69.30 \\
\hline 3 & 77.5 & 66.55 & 11801 & 64.52 & 133.82 \\
\hline 4 & 65.4 & 60.54 & 12273 & 91.92 & 225.74 \\
\hline 5 & 51.7 & 53.72 & 12763 & 124.81 & 350.55 \\
\hline 6 & 36.5 & 46.18 & 13274 & 163.47 & 514.02 \\
\hline 7 & 95.7 & 75.55 & 13805 & 33.71 & 547.73 \\
\hline 8 & 87.8 & 71.63 & 14357 & 53.98 & 601.71 \\
\hline 9 & 77.6 & 66.55 & 14931 & 81.64 & 683.35 \\
\hline 10 & 65.4 & 60.54 & 15529 & 116.31 & 799.66 \\
\hline
\end{tabular}


Table (6) Section 4; the yearly and accumulated emissions for thin overlay

\begin{tabular}{|c|c|c|c|c|c|}
\hline Year & PCI & Speed (S) & $\begin{array}{c}\text { Yearly } \\
\text { Traffic }\end{array}$ & $\begin{array}{c}\text { Yearly "E" } \\
\text { ton/km' }\end{array}$ & $\begin{array}{c}\text { Accumulated Yearly "E" } \\
\text { 'ton/km' }\end{array}$ \\
\hline 1 & 95.7 & 75.55 & 18612 & 45.45 & 45.45 \\
\hline 2 & 87.8 & 71.63 & 19357 & 72.78 & 118.23 \\
\hline 3 & 77.5 & 66.55 & 20131 & 110.05 & 228.28 \\
\hline 4 & 65.4 & 60.54 & 20936 & 156.77 & 385.05 \\
\hline 5 & 99.3 & 77.36 & 21774 & 39.86 & 424.91 \\
\hline 6 & 98.1 & 76.77 & 22644 & 45.99 & 470.90 \\
\hline 7 & 96.6 & 75.99 & 23550 & 53.93 & 524.83 \\
\hline 8 & 94.8 & 75.08 & 24492 & 63.61 & 588.45 \\
\hline 9 & 99.3 & 77.36 & 25472 & 46.63 & 635.08 \\
\hline 10 & 98.1 & 76.77 & 26491 & 53.80 & 688.88 \\
\hline
\end{tabular}

Tabie (7) Section 5; the yearly and accumulated emissions for reconstruction

\begin{tabular}{|c|c|c|r|c|c|}
\hline Year & PCI & Speed (S) & $\begin{array}{c}\text { Yearly } \\
\text { Traffic }\end{array}$ & $\begin{array}{c}\text { Yearly "E" } \\
\text { 'on } / \mathrm{km}^{\prime}\end{array}$ & $\begin{array}{c}\text { Accumulated Yearly "E" } \\
\text { 'ton/km' }\end{array}$ \\
\hline 1 & 95.8 & 75.54 & 11478 & 28.03 & 28.03 \\
\hline 2 & 87.8 & 71.62 & 11937 & 44.88 & 72.90 \\
\hline 3 & 77.5 & 66.55 & 12414 & 67.88 & 140.78 \\
\hline 4 & 65.4 & 60.54 & 12911 & 96.70 & 237.48 \\
\hline 5 & 51.7 & 53.72 & 13427 & 131.29 & 368.77 \\
\hline 6 & 36.5 & 46.18 & 13964 & 171.97 & 540.74 \\
\hline 7 & 95.7 & 75.55 & 14523 & 35.46 & 576.21 \\
\hline 8 & 87.8 & 71.63 & 15104 & 56.78 & 632.99 \\
\hline 9 & 77.5 & 66.55 & 15708 & 85.89 & 718.87 \\
\hline 10 & 65.4 & 60.54 & 16336 & 122.29 & 841.17 \\
\hline
\end{tabular}

Table (8) Section 6; the yeariy and accumulated emissions for thin overlay

\begin{tabular}{|c|c|c|r|c|c|}
\hline Year & PCI & Speed (S) & $\begin{array}{c}\text { Yearly } \\
\text { Traffic }\end{array}$ & $\begin{array}{c}\text { Yearly "E" } \\
\text { 'ton/km' }\end{array}$ & $\begin{array}{c}\text { Accumulated Yearly "E" } \\
\text { 'ton/km' }\end{array}$ \\
\hline 1 & 95.7 & 75.55 & 26263 & 64.13 & 64.13 \\
\hline 2 & 87.8 & 71.63 & 27314 & 102.69 & 166.82 \\
\hline 3 & 77.5 & 66.55 & 28406 & 155.32 & 322.13 \\
\hline 4 & 65.4 & 60.54 & 29542 & 221.16 & 543.29 \\
\hline 5 & 99.3 & 77.37 & 30724 & 56.30 & 599.59 \\
\hline 6 & 98.1 & 76.77 & 31953 & 64.85 & 664.43 \\
\hline 7 & 96.5 & 75.99 & 33231 & 76.17 & 740.60 \\
\hline 8 & 94.7 & 75.08 & 34560 & 89.82 & 830.42 \\
\hline 9 & 99.4 & 77.36 & 35943 & 65.86 & 896.28 \\
\hline 10 & 98.2 & 76.77 & 37380 & 75.86 & 972.14 \\
\hline
\end{tabular}


Fathy Mahmoud Mandeel, "The Impact of Pavement Condition on the Traffic Environment Pollution"

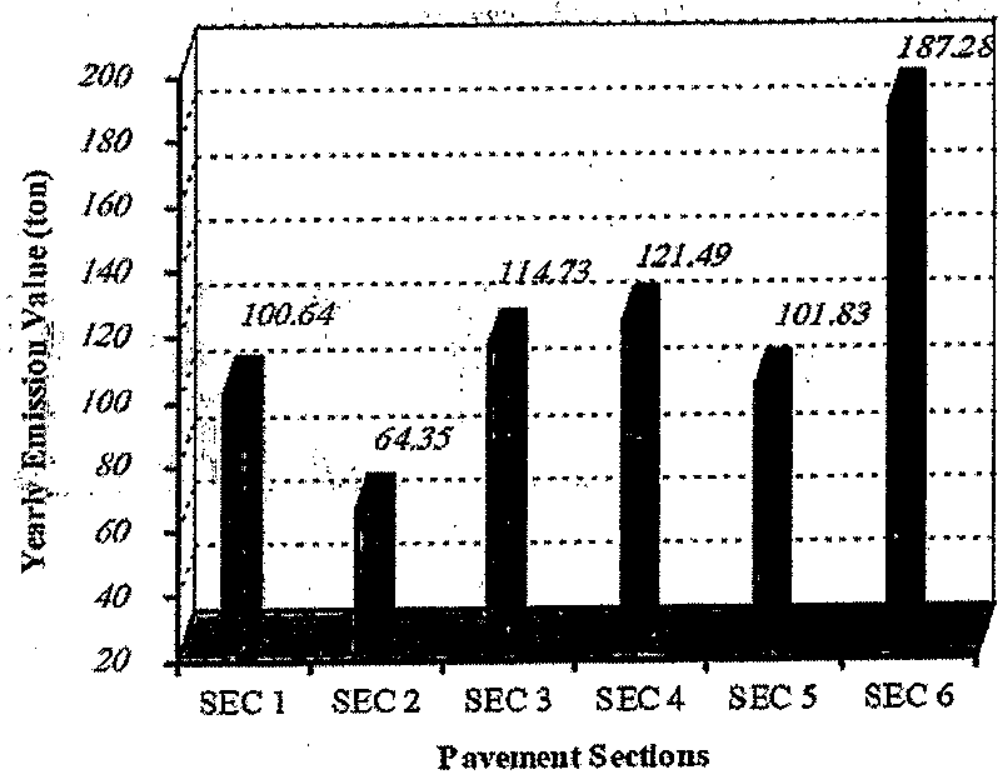

Figure (1) yearly emission value for different pavement sections

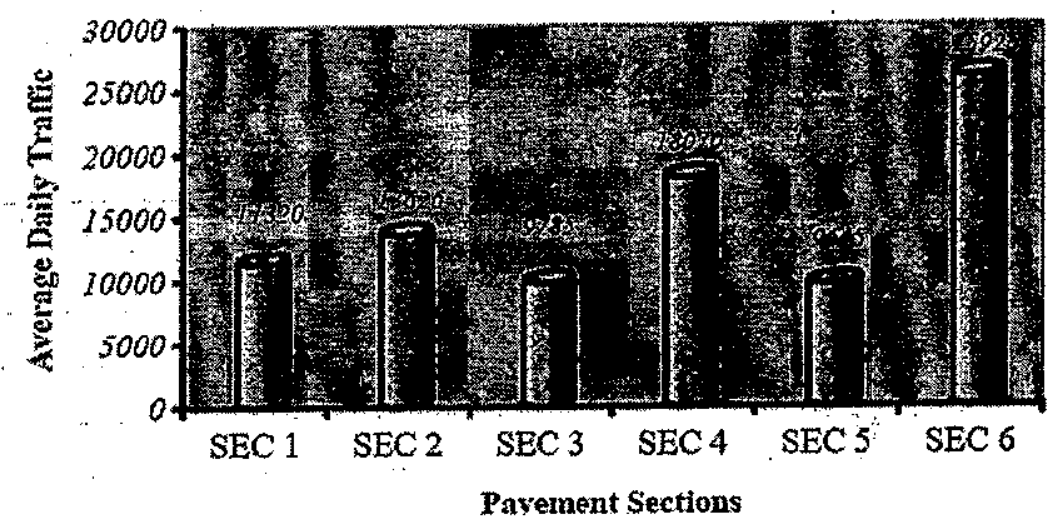

Figure (2) ADT for different pavement sections

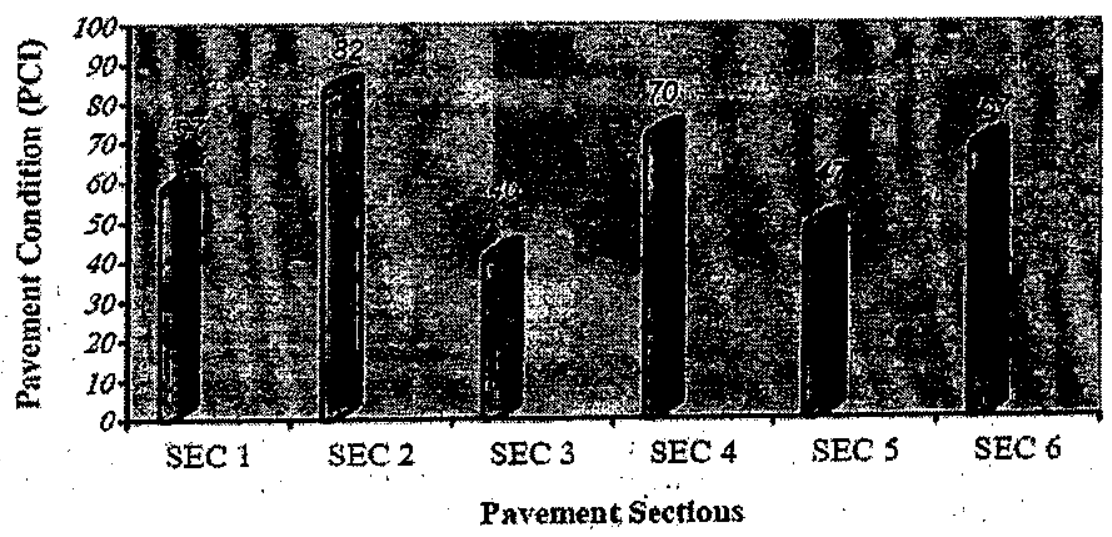

Figure (3) Pavement Condition for different Pavement Sections 


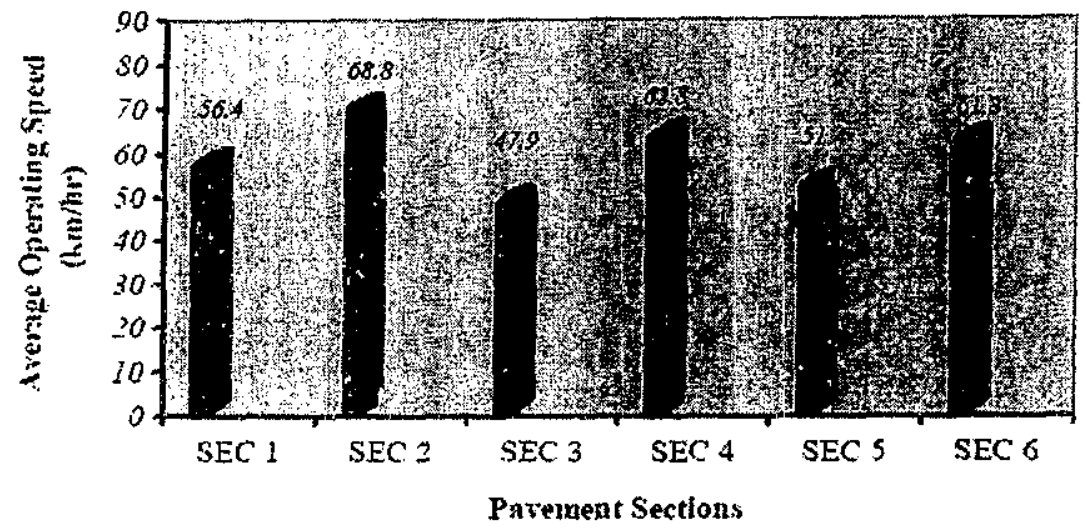

Figure (4) average operating speed at different Pavement Sections

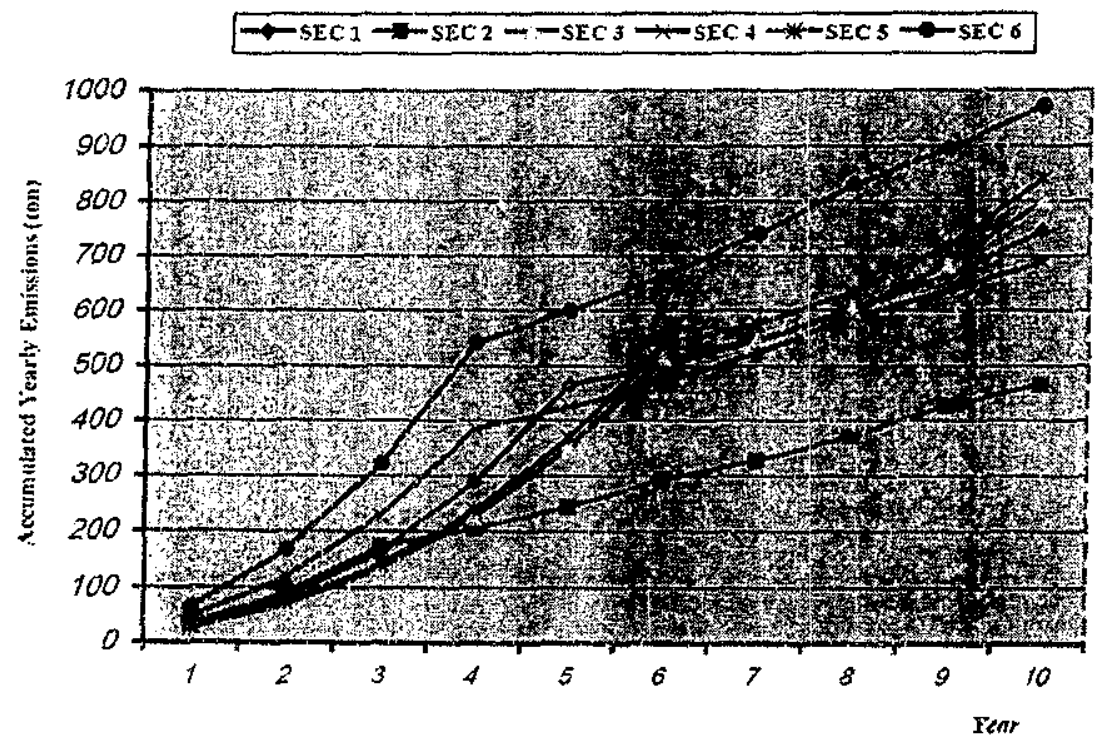

Figure (5) the accumulated annual emission (ton) for different pavement sections

\section{CONCLUSIONS AND RECOMMENDATIONS}

This paper concerned with the environmental issues represented by air emission result from traffic related to pavement condition. Three relations were used; first, simple performance models for different pavement maintenance types, second, relation between pavement condition and traffic speed and third, quantification of air pollution results from traffic speed reduction. The description of procedure steps to correlate different relations for emission calculation result from different maintenance techniques was discussed. Thereafter, an application case was done and the following tesults were concluded:

1- Section 6 produces the highest yearly emission (187.28) ton as a result of higher traffic volume although the pavement "condition is good ( see Table 2 \& Figure 1)

2- The lowest yearly emission came from section 2 (64.35ton) as a result of a very good pavement condition.

3- The lowest condition of section 3 \& section 5 generates high emissions (114.73\&101.83 ton) respectively although their lowest traffic volume.

4- As a result of condition status of sections $3 \& 4$, which is (poor \& very good) respectively, the emission values are approximately closed together although the traffic volume for section 4 almost the double of it for section 3 .

5- On the long-run, after application of the suitable maintenance type (see Figure 5), the descending ranking of cumulative emissions value within the 
life cycle are; $972.14,841.17,799.66,744.57$, 688.88 and 466.58 ton for sections $6,5,3,1,4$ and 2 respectively. The highest emissions of section 6 came from highest traffic volume and deficient condition. The worst condition of sections 5, 3 and 1 respectively is the major reason of increasing the emissions.

6- Finally, we can say that as the pavement condition deteriorates, traffic speed is reduced and subsequently the emission of vehicles tends to increase.

Hence, we recommend the following;

1. Pavement maintenance strategies should be applied to keep the pavement condition as nearly as its original state to protect the health of people and then the economy of the country against pollution.

2. In depth studies are required to correlate the effect of traffic pollution on the health of people, and to predict the relations between vehicle types, speed, pavement condition and the road type.

3. Environment pollution and human health costs must be included in the strategic of pavement maintenance management techniques.

\section{REFERENCES}

[1] R.K. Seethaler Institute of Transport Studies, University of Sydney 2006 NSW Australia Transportation "Health Costs due to RoadTraffic-Related Air Pollution: An impact assessment project of Austria, France and Switzerland Author(s): Research Board 79 th Annual Meeting January 9-13, 2000 Washington, DC.

[2] Pope CA, Thun M, Noboodiri M, et al, (1995); Particulate air pollution as a predictor of mortality in a prospective study of U.S. Adults. Am J Respir Crit Care Med 1995; 151(3): 669-74

[3] Spix C, Anderson HR, Schwartz J, et al. (1998); Short-term effects of air pollution on hospital admissions of respiratory diseases in Europe: a quantitative summary of APHEA study results. Arch Environ Health 1998; 53:54-64 Seethaler 9

[4] Wordley J, Walters S, Ayres JG. (1997); Short term variations in hospital admissions and mortality and particulate air pollution. Occup Environ Health 1997; 54: 108-116

[5] Poloniecki JD, Atkinson RW, Ponce de Leon A, Anderson HR. (1997); Daily time series for cardiovascular hospital admissions and previous day's air pollution in London, UK. Occup Environ Health 1997; 54: 535- 540

6. Dockery DW, Speizer F, Stram D et al. (1998); Effects of inhalable particles on respiratory health of children. Am Rev Respir Dis 1989; 139:587-94.

[7] Hongchang Zhou , Transportation Research Board, "Vehicular Emission Pollution and Control Strategy in China", , Institute of Transportation Studies, University of California, Davis, CA95616, 79 th Annual Meeting, January 9-13,2000, Washington,D.C.

[8] Ralph Hass, W.Ronald .Hudson, John Zan,"Modern Pavement Management", KRIEGER Publishing Company MALABAR, Florida, 1994.

[9] Sharaf, E. A., "A Simple Procedure to Select Best Maintenance Alternatives in Developing Countries", Transportation Research Record No 1034, Transportation Research Board 1991.

[10] International Road Federation (IRF), "Third Executive Conference on Motor Vehicles and The Environment", Orlando, Florida 1994.

[11] Alberta Transportation, "Guidelines for assessing Pavement Maintenance Strategy", Alberta Transportation, June 2002.

[12] AASHTO Standing Committee on Highways, 1997.

[13] Hahin, M.Y and Kohn, S.D., "Pavement Maintenance Management for Roads and Parking Lots", United States Army, Corps of Engineers, Technical Report M-294, 1981. 



\title{
STRENGTH AND ABRASION RESISTANCE OF RECYCLED LEAD SLAG MORTAR AT HIGH TEMPERATURES
}

\author{
M. H. Seleem \\ Materials Engineering Department, Zagazig University, Zagazig, Egypt.
}

\begin{abstract}
The effect of high termperatures on the compressive strength and abrasion resistance of mortar fabricated by using lead slag extracted from recycling of the spent batteries in the homely workshops as fine aggregates was experimentally investigated. The fine lead slag (FLS) was used as a partial replacement of the total fine aggregate (TFA), sand, by different percentages of volume (FLS/TFA $=0,10,20,30$ and 40\%). Test specimens were subjected to high temperatures ranging from $200^{\circ} \mathrm{C}$ to $700^{\circ} \mathrm{C}$ step $100^{\circ} \mathrm{C}$. The exposure time after reaching the desired target temperature kept at two hours. The sequence of the residual unstressed test was followed. The weight loss and the relative compressive strength (strength of heated specimen to that of the corresponding unheated specimen) were determined. The weight loss of the heated and unheated specimens due to exposure to abrasive wear was also calculated. Test results indicated that, at certain FLS/TFA\%, the relative compressive strength decreased gradually with high temperature up to $500^{\circ} \mathrm{C}$ and after that it showed a sudden drop with further increases in temperature. The abrasion resistance decreased with increasing high temperature. The compressive strength and abrasion resistance of mortar increased up to replacement of $20 \%$ of sand by FLS and after that it decreased but still higher than that of $100 \%$ sand. Both compressive strength and abrasion resistance of FLS mortar relative to those of $100 \%$ sand enhanced clearly with the presence of FLS at temperature above" $500^{\circ} \mathrm{C}$

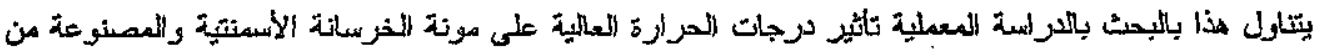

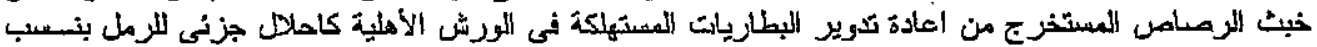

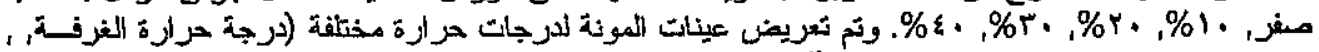

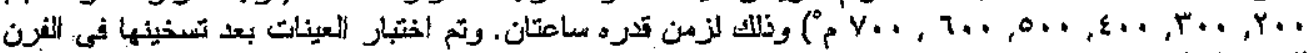

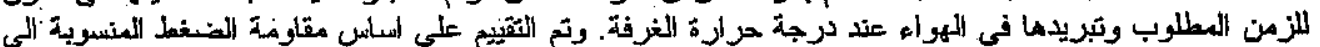

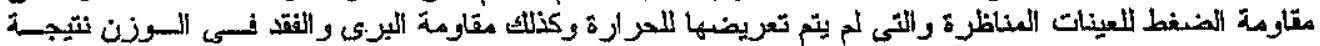

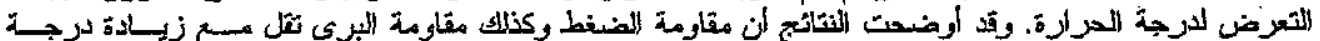

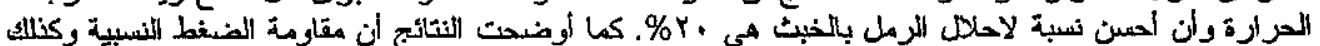

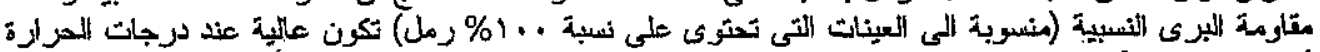

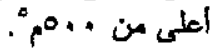

Keywords: Recycled lead-slag; Mortar; High temperature; Compressive strength; Abrasion resistance.

\section{INTRODUCTION}

The high consumption of natural sources, the high amount of industrial wastes and environmental pollution require new solutions for a sustainable development. One of the major contributions to the preservation of the environment and sustainable development is the reuse and recycling of the waste materials. Use of inorganic industrial residual products in making cementations products as concrete and mortar will lead to sustainable concrete design and a greener environment [1].

The need to develop concrete and mortar with nonconventional aggregates is urgent for environmental as werl as economic reasons. A review of earlier research showed that industrial as well as other wastes have been used in concrete-making to improve the properties of concrete and to reduce cost. Inclusion of recycled tire rubber fibers in concrete was found to avoid the opening of cracks and increase energy absorption [2]. Structural light weight concrete has been produced using oil palm shells [3] and demolished masonry waste [4] as aggregates. An improvement in the modulus of elasticity of concrete was observed. with partial replacement of crushed stone coarse aggregate by crushed vitrified soil aggregate [5].

Compressive strength and abrasion resistance were increased when crushed ceramic waste was used to partially replace conventional gravel coarse aggregate [6]. On the other hand, De Brito et al [7] 
found that strength decreases as the quantity of ceramic aggregates in concrete increases and the decrease in compressive strength is higher than that in the flexural strength. While, the abrasion resistance of concrete made with ceramic recycled aggregates is higher than that of concrete made with limestone aggregates. Durability of cementatious materials like mortar and concrete is as important as compressive strength.

In recent publisned work by the author and coworkers [8], lead slag extracted from recycling of the spent batteries in the homely workshops was used as concrete aggregate. Short term mechanical properties, wear resistance and radiation absorption were studied. In the same year, Penpolcheroen [9] published the second contribution in the use of secondary lead slag as a construction material. He found that all samples exhibited higher compressive strengths than that of the sample without slag, which increased with increasing the slag contents and ages. The highest compressive strength was found for the sample containing $20 \%$ slag as cement replacement and $100 \%$ slag as aggregate replacement.

The results of chemical analysis of the used lead slag in the previous work $[8,9]$ revealed that the oxide components of the slag were similar to those of ordinary Portland cement (OPC). For environmental concen, leachability of lead (Pb) from all samples was also carried out [9] on samples with high slag content. The amounts detected were much lower than the acceptable limit $(5 \mathrm{ppm})$ for the requirement of Thai hazardous waste disposal standard. So, the application of the slag for construction material is fully attractive. The environmental conditions such as temperature, humidity and the mechanism of chemical transports are the major factors causing chemical and physical attacks [10]. Thus, the performance of construction materials fabricated from slag under these conditions is of primary important. So, in the present work, the effect of high temperature on the compressive strength and abrasion resistance of mortar made with lead slag as partial replacement of sand was studied.

\section{EXPERIMENTAL WORK}

All materiais used in this study were locally available materials. The cement used was type I ordinary Portland cement. The sand was siliceous sand with $100 \%$ passing ASTM sieve No. 4 . The fine lead-slag (FLS) used in this research was obtained by recycling of the spent batteries electrodes in homely workshops. Recycled- lead slag (RLS) was used as fine aggregate in mortar manufacture. The RLS was crushed to the desired gradation by using a roller mill. An energy dispersive X-ray spectroscope was performed to analyze the chemical compositions of the materials. The results of chernical analysis of the used FLS and OPC are given in Table 1. The physical and mechanical properties of the used fine aggregate (sand and FLS) are given in Table 2 . Mixing water was clcan tap water free from impurities and organic matters. The sand: cement ratio was $3: 1$ by weight and the water cement ratio was 0.5 . The total fine aggregates (TFA) in the mix were partially replaced by FLS particles. The percentages by volume of FLS/TFA were $0,10 \%$, $20 \%, 30 \%$, and $40 \%$.

Table 1 Chemical composition of FLS and OPC

\begin{tabular}{|c|c|c|}
\hline Constituent & FLS $(w t \%)$ & OPC $(w t \%)$ \\
\hline $\mathrm{CaO}$ & 2.5 & 62 \\
\hline $\mathrm{SiO}_{2}$ & 12.98 & 20.39 \\
\hline $\mathrm{Al}_{2} \mathrm{O}_{3}$ & - & 5.05 \\
\hline Iron oxide & $\begin{array}{c}72.8 \\
\text { as } \mathrm{Fe}_{3} \mathrm{O}_{4}\end{array}$ & $\begin{array}{r}2.89 \\
\text { as } \mathrm{Fe}_{2} \mathrm{O}_{3}\end{array}$ \\
\hline $\mathrm{MgO}$ & 0.26 & 2.07 \\
\hline $\mathrm{K}_{2} \mathrm{O}$ & 0.21 & 0.5 \\
\hline $\mathrm{Na}_{2} \mathrm{O}$ & 0.53 & 0.07 \\
\hline $\mathrm{SO}_{3}$ & $=$ & 2.4 \\
\hline $\mathrm{MnO}$ & 0.46 & - \\
\hline $\mathrm{Pb}$ & 4.1 & $=$ \\
\hline Others & 2.33 & 1.53 \\
\hline L.O.I & 3.83 & 3.1 \\
\hline
\end{tabular}

Table 2 Physical properties of sand and FLS

\begin{tabular}{|c|c|c|}
\hline Property & Sand & FLS \\
\hline Specific gravity & 2.45 & 4.28 \\
\hline \multicolumn{3}{|l|}{ Density, $\mathrm{kg} / \mathrm{m}^{3}$} \\
\hline Loose & 1610 & 2280 \\
\hline Dense & 1700 & 2820 \\
\hline \multicolumn{3}{|l|}{$\%$ Voids } \\
\hline Loose & $38 \%$ & $47 \%$ \\
\hline Dense & $27 \%$ & $34 \%$ \\
\hline$\%$ Water absorption & 0.42 & 3.95 \\
\hline $\mathrm{FM}$ & 2.55 & 3.35 \\
\hline
\end{tabular}

Batch materials required for casting twenty one cubes (70 mm side length) for compression test and twenty one cylinders (25 mm diameter and $25 \mathrm{~mm}$ height) for abrasive wear test were weighted first. Dry materials for this batch were mixed in the dry state for a time to insure the homogeneity of the mixture before adding the mixing water. The test specimens were removed from the moulds 24 hours after casting and immediately submersed in the curing water for 28 days. A total number of 105 compression specimens and 105 abrasion specimens representing five mixes having different FLS/TFA\% were tested.

The experimental program suggested for the present work included the exposure of the mortar specimens 


\section{H. Seleem, "Strength and Abrasion Resistance of Recycled Lead Slag Mortar At High Temperatures"}

to different target temperatures (TT) ranging from $200^{\circ} \mathrm{C}$ to $700^{\circ} \mathrm{C}$ step $100^{\circ} \mathrm{C}$ at an average heating rate of about $10^{\circ} \mathrm{C} / \mathrm{min}$. An electric furnace of $1600^{\circ} \mathrm{C}$ maximum temperature was used. The specimens were placed inside the furnace and the temperature was raised until it reaches the desired target temperature. The specimens were sustained at this target temperature for 2 hours. Affer that they allowed to cool outside the furnace at room temperature (residual unstressed test sequence), Fig. 1. All cubes specimens were weighted before and after heating to calculate the mass loss due to heating.

A universal-testing machine of $1000 \mathrm{kN}$ maximum capacity was used for the compression test. Among test methods suggested by ASTM for the estimation of the wear resistance of cementitious materials, the revolving disk. (ASTM C779, Procedure A) test method [11] was selected. An aggregate abrasion testing machine (Cat.' No. EL 42-500) was used to perform the test. The test specimens were exposed to abrasive standard sand, passed from $0.6 \mathrm{~mm}$ sieve and retained on $0.45 \mathrm{~mm}$ sieve, for 500 revolutions under a load of $750 \mathrm{gm}$. Each specimen was weighted before and after the test and the weight loss was calculated.
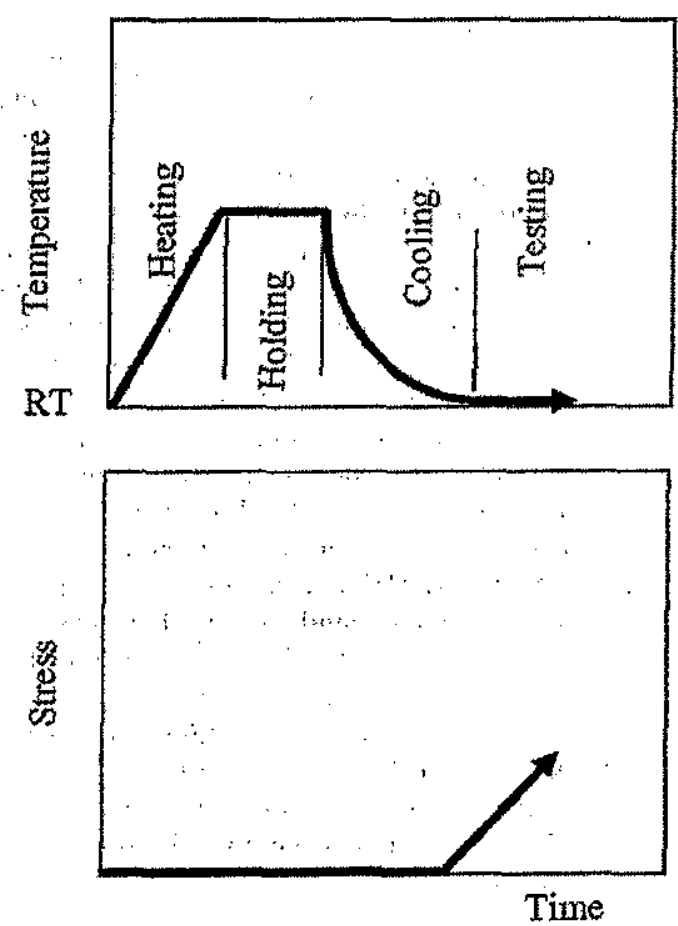

Fig. 1 Sequence of residual unstressed test followed in this work

\section{RESULTS AND DISCUSSIONS}

\section{Density}

The effect of FLS/TFA \% on the relative density of mortar is illustrated in Fig. 2. The relative density is the ratio of the density of mortar specimen with sand replaced by FLS to that of $100 \%$ sand specimen. The addition of FLS to mortar results in a linear increase in the density of the material to reach $20 \%$ higher than that of $100 \%$ sand at FLS/TFA $\%$ equal to $40 \%$.

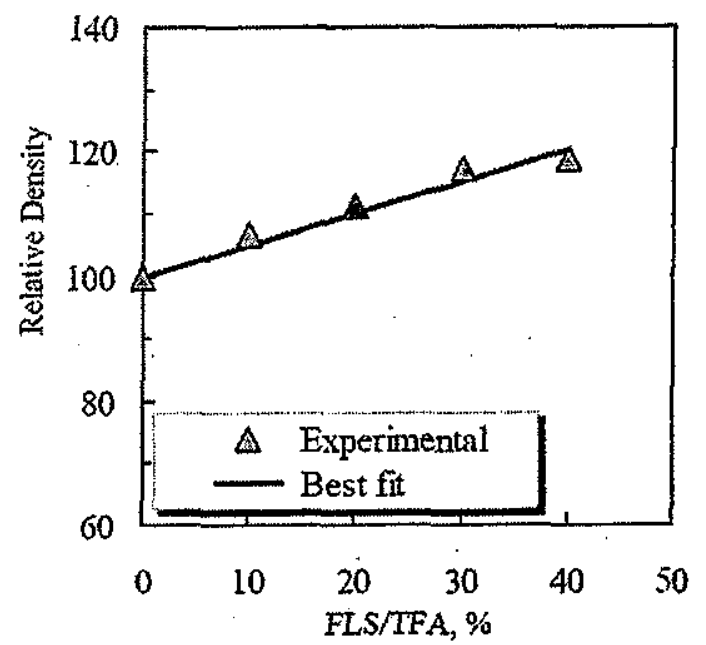

Fig. 2 Effect of FLS/TFA \% on the hardened density of concrete mortar.

\section{Mass Loss}

The mass losses for the different mortar specimens due to water evaporation as a result of exposure to high temperatures are shown in Fig. 3 for the different FLS/TFA \%. The relative mass losses were estimated as the difference in the mass between the unheated and heated specimens to that of the unheated specimens. An increase in the relative mass loss was observed for all mixtures with increasing temperature. The loss rate is high at low temperatures up to $300^{\circ} \mathrm{C}$, after that it stabilized before increasing again above $500^{\circ} \mathrm{C}$. Similar behavior was observed for concrete specimens but the stabilized stage was ranged between $200^{\circ} \mathrm{C}$ and $400^{\circ} \mathrm{C}$ [12]. It is also clear that the mix of FLS/TFA equal to $10 \%$ showed the highest relative mass loss, while that of $40 \%$ FLS recorded the lowest relative mass loss. The mass loss at low temperatures, below $300^{\circ} \mathrm{C}$, is caused by quick evaporation of capillary water. Over $400^{\circ} \mathrm{C}$, the mass loss is caused by evaporation of chemically combined water (dehydration) and decomposition [13]. Above temperature of $500^{\circ} \mathrm{C}$, the dehydration of the chemically combined water of the hydrated Calcium Silicate Hydrate (CSH) resulting in unhydrated products was accompanied by observable mass loss. 


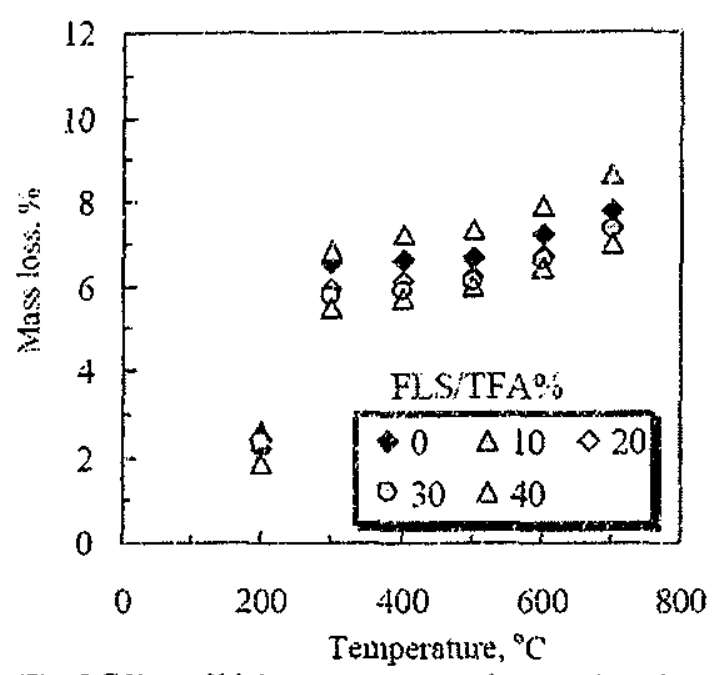

Fig. 3 Effect of high temperature on the mass loss for different FLS/TFA \%.

\section{Compressive Strength}

The effect of high temperature on the relative compressive strength of mortar specimens with FLS/TFA equal to $0 \%, 10 \%, 20 \%, 30 \%$ ard $40 \%$ is shown in Fig. 4. The relative compressive strength here is defined as follows:

Relative compressive strength $=\left[\sigma_{\mathrm{cHT}} / \sigma_{\mathrm{cRT}}\right] \times 100$

Where $\sigma_{\mathrm{cHT}}$ is the compressive strength of the specimen exposed to the desired target temperature and $\sigma_{\mathrm{CRT}}$ is the corresponding compressive strength of the unheated specimens at the same FLS $/ \mathrm{TFA} \%$. The general trend for the different FIS/TFA \% is similar, i.e. with increasing the target temperature, a steady state drop in the relative strength is observed up to a temperature of $500^{\circ} \mathrm{C}$, where the average relative strength is about $83 \%$. After $500^{\circ} \mathrm{C}$, the average relative strength dropped suddenly to reach $51 \%$ with increasing temperature to $600^{\circ} \mathrm{C}$. At $700^{\circ} \mathrm{C}$, the relative strength reached an average of $36 \%$. At temperature of $200^{\circ} \mathrm{C}$, the average relative strength is $96 \%$. In a previous work by the author and coworkers [12] on the effect of high temperature on the relative strength of concrete, a sudden drop was recorded in the strength after $200^{\circ} \mathrm{C}$ and gravel concrete completely lost its strength at $600^{\circ} \mathrm{C}$. The absence of coarse aggregate in the mortar decreased the effect of differential thermal expansion that occurred between cement paste and aggregate. This can explain the slow gradual decrease in the relative strength at temperature up to $500^{\circ} \mathrm{C}$. The high relative strength at $200^{\circ} \mathrm{C}$ is attributed to the enforced hydration process due to water evaporation [14]. The structure of the cement mortar after high temperature exposure gets loose because of the pore expansion owing to the vaporization of the absorbed water. The loss of water from the free calcium hydroxide (CH) (results from cement hyuration), leaving calcium oxide (quick îme). This calcium oxide absorbs water from the surrounded atmosphere as the specimen leaved cool. Thus it re-hydrated to $\mathrm{CH}$ or reacts with atmospheric $\mathrm{CO}_{2}$ resulting in calcium carbonate $\left(\mathrm{CaCO}_{3}\right)$. Theses processes are accompanied by an expansion in the volume, which may disrupt the material $[13,15]$.

To explain the role of FLS/TFA $\%$ on controlling the behavior of mortar at high temperature, the compressive strength of the heated mortar specimen with different FLS/TFA\% $\left(\sigma_{c}\right)$ was divided to that with FLS/TFA\% equal to $0\left(\sigma_{c o}\right)$ at the different regimes of high temperatures including $\mathrm{RT}$ as shown in Fig. 5. The effect of FLS/TFA\% at different temperatures shows sımilar trends, i.e. an increase in the strength ratio as the FLS/TFA\% increases up to FLS/TFA $=20 \%$ and after that it decreases to approach that at $0 \%$ FLS/TFA at FLS/TFA \% equal to $40 \%$. Also it is clear that the strength ratio increases as the exposed temperature increases especially at temperatures of 600 and $700^{\circ} \mathrm{C}$ for all FLS/TFA \%. As an example for FLS/TFA $\%$ equal to $20 \%$, the strength ratio reached 1.12 at $200^{\circ} \mathrm{C}, 1.18$ at $500^{\circ} \mathrm{C}$ and 1.60 at $700^{\circ} \mathrm{C}$. The FLS shows some of hydration reactivity, which allows it to behave as a pozzolanic when it was mixed with cement. So, using of leadslag as aggregate enhances a type of aggregate cement paste interface. The decrease in the strength with further increase in the replacement of sand by FLS may be due to the fact that by increasing the fine lead-slag aggregate without the equivalent required amount of cement to achieve pozzolanic hydration, an adverse effect on the bond in the matrix is occurred [9]. At high temperatures, the reduced amount of $\mathrm{Ca}(\mathrm{OH}) 2$ due to the pozzolanic effect of FLS increase the strength ratio at those temperatures, which otherwise results in strength loss and disintegration [16]. Photo.1 shows the crack pattem of the mortar specimens after exposed to temperature of $700^{\circ} \mathrm{C}$ for FLS/TFA equal to 0 and $20 \%$. A wide crack is observed on the specimen surface for FLS/TFA\% equal to 0 compared to a very narrow surface cracks in the case of FI.S/TFA equal to $20 \%$. 
M. H. Seleem, "Strength and Abrasion Resistance of Recycled Lead Slag Mortar At High Temperatures"
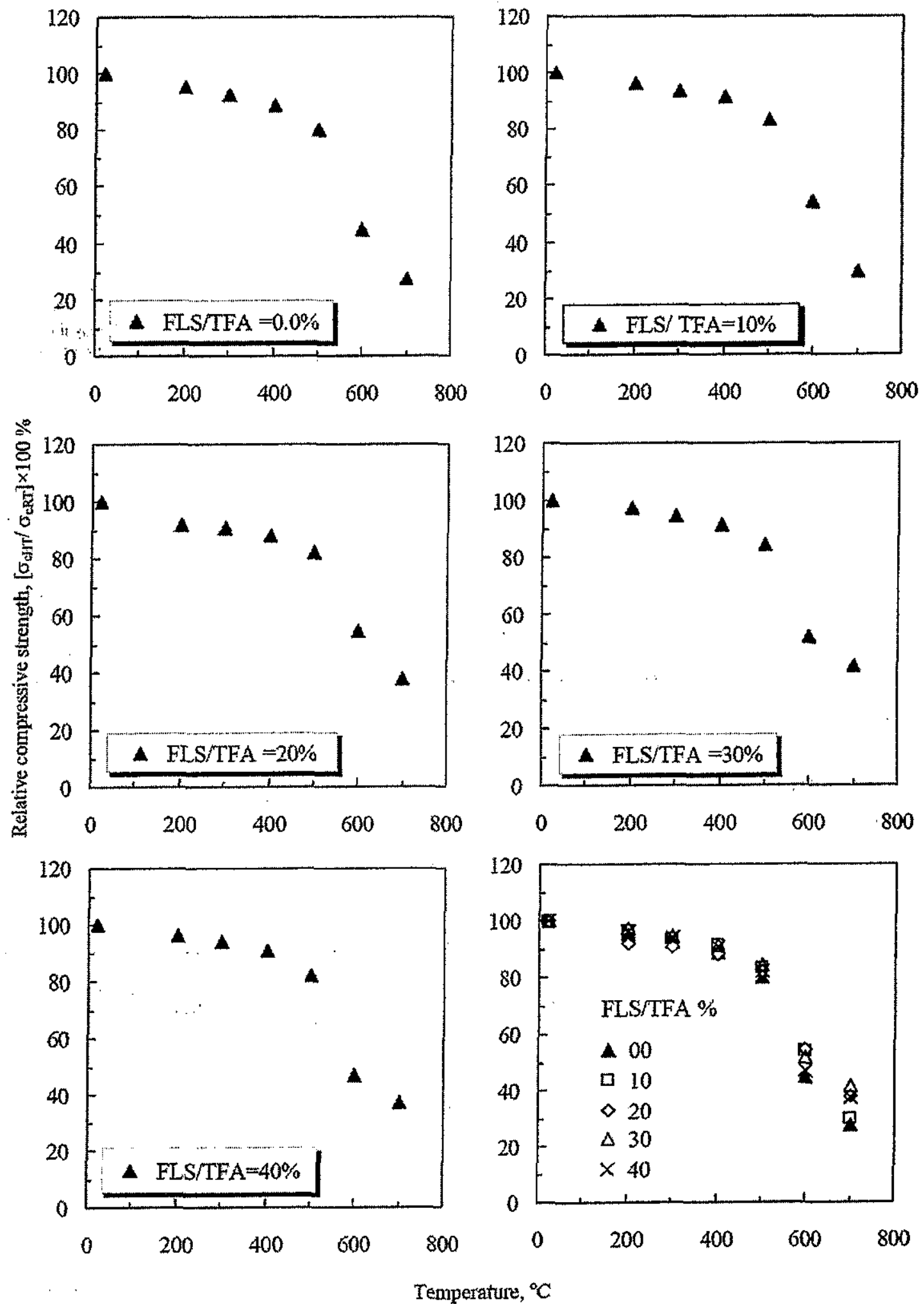

Fig. 4 Relative compressive strength against temperatures for different FLS/TFA\%. 

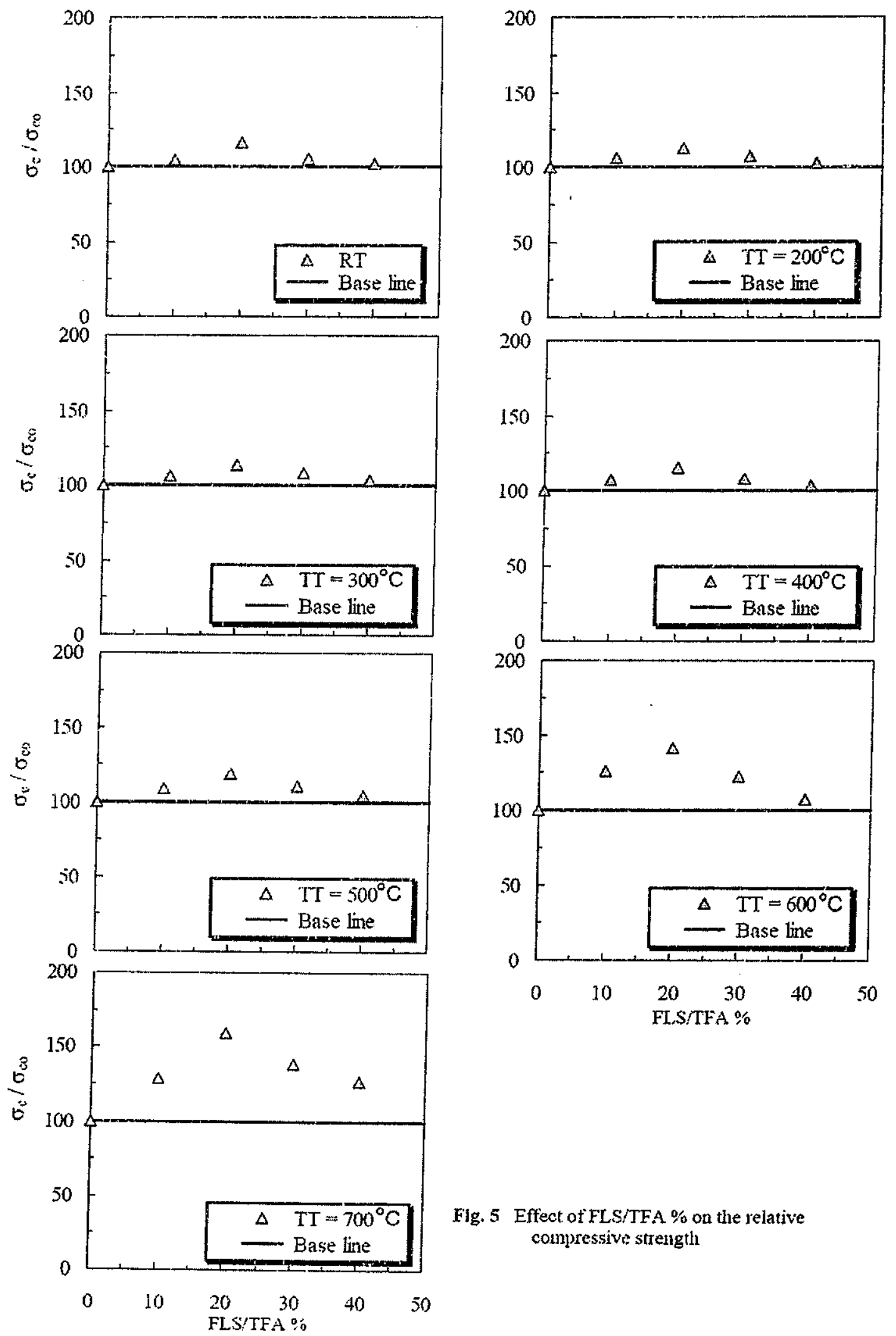

Fig. 5 Effect of FLS/TFA \% on the relative compressive strength 

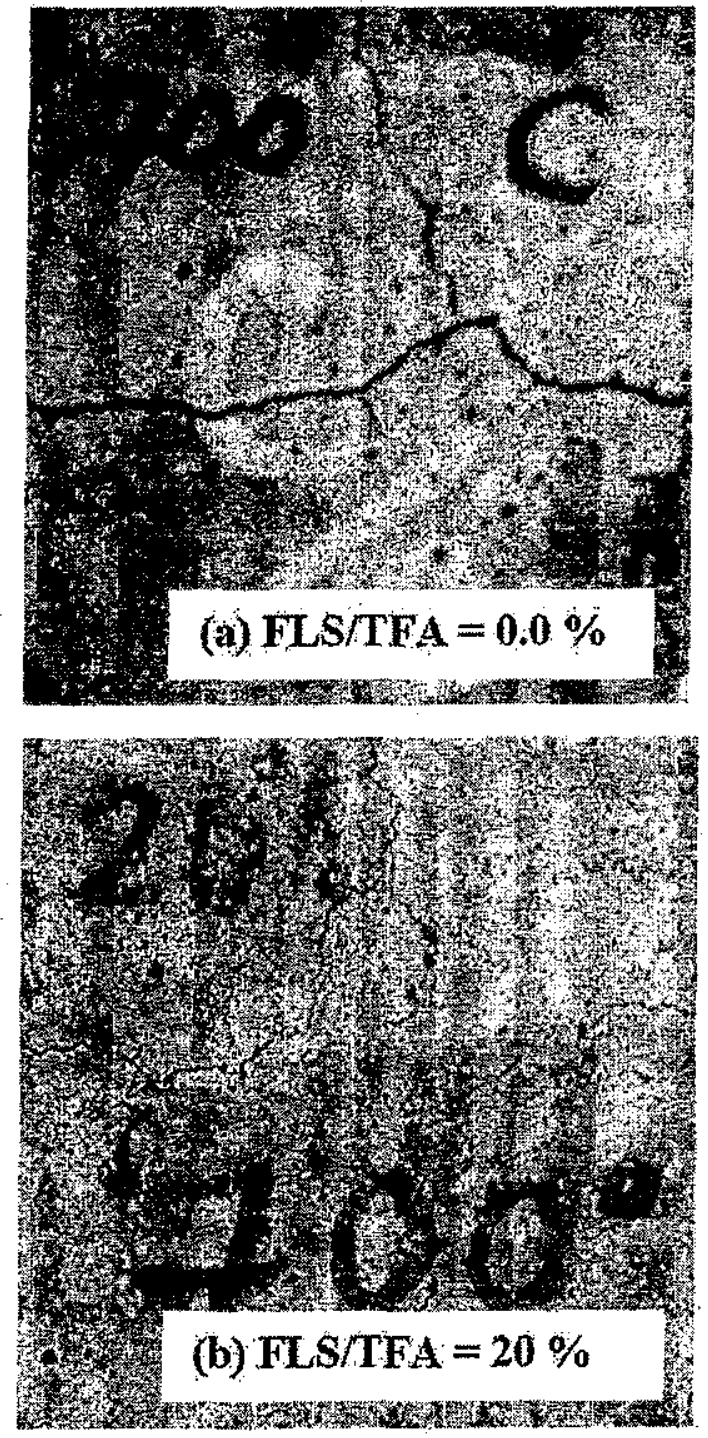

Photo. 1 Crack pattern of mortar specimens after heating to $700 \circ \mathrm{C}$ for

a) FLS/TFA $=0.0 \%$ and

b) $\mathrm{FLS} / \mathrm{TFA}=20 \%$.

\section{Abrasion Resistance}

The effect of high temperature on the abrasion resistance of mortar fabricated by partial replacement of sand by different percentages of FLS/TFA is shown in Fig. 6. The abrasion resistance defined by the wear rate (WR) is expressed as the weight loss of the tested specimen divided by the area of the surface exposed to wear. This is of a physical meaning, since abrasion is a surface property that defines surface layer characteristics. The exposed surface area for all specimens is constant and equal to the area of a circle having a diameter of $25 \mathrm{~mm}$. The unit now is $\mathrm{gm} / \mathrm{mm}^{2}$. Fig. 6 shows the relation between the relative wear rate (wear rate of specimens exposed to heat multiplied by 100 and divided by that of the unheated specimens at the same FLS/TFA\%). The figure shows increases in the relative wear rate with increasing temperature for all FLS/TFA\%. This means a decrease in the abrasion resistance with increasing temperature and the relation is approximately linear. This trend is similar to that of compressive strength.

To reflect the effect of FLS/TFA\% of the abrasion resistance of mortar at different temperature, the wear rate ratio (the ratio of the wear rate of mortar specimen containing FLS to that of $100 \%$ sand at the same temperature) is drawn in Fig. 7 against FLS/TFA\% for different temperatures considered. The presence of FLS enhances the abrasion resistance of mortar specimens up to $20 \%$ replacement and after that the effect decreases until it approximately match that of $100 \%$ sand at FLS/TFA equal to $40 \%$. The role of FLS replacement is more pronounced at high temperatures above $500^{\circ} \mathrm{C}$.

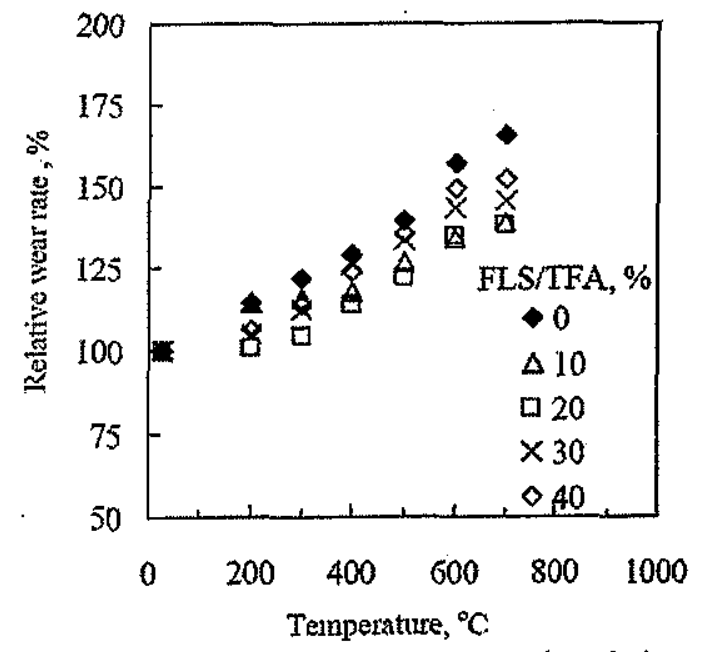

Fig. 6 Effect of high temperature on the relative abrasion rate for different FLS/TFA \%.

The presence of FLS, which behaves as a pozzolanic material reacts with the hydration products forming and thus enhances cement aggregate interface and leads to dense structure composed of irregular grains and hydrated products attach to the aggregate surface strongly. This improves the resistance of the mortar to abrasive wear. With the increase in FLS above $20 \%$, the remaining un-reacted FLS behaves as filler and which can easy leave the surface of the specimen during abrasion. 


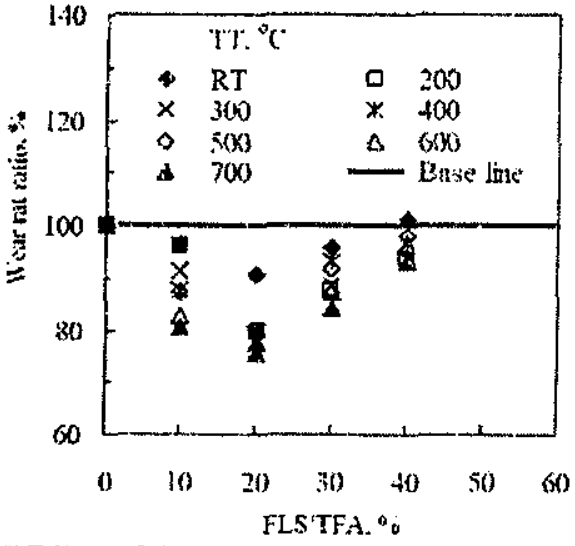

Fig. 7 Effect of FLS/TFA \% on the wear rate ratio at different high temperatures.

\section{CONCLUSIONS}

1. The compressive strength of fine lead slag mortar decreased gradually with increasing temperature up $500^{\circ} \mathrm{C}$ and after that temperature the strength decreased narkedly.

2. With increasing fine lead slag percent as a partial replacement of sand, the compressive strength increased up to fine lead slag percent of $20 \%$ and after that it decreases but still higher than that of $100 \%$ sand at $40 \%$ fine lead slag.

3. The presence of fine lead slag played a vital role in enhancing the strength ratio of lead slag mortar compared to those of sand mortar especially at high temperatures above $500 \mathrm{aC}$.

4. The abrasion resistance of plain and lead siag mortar decreased linearly with increasing high temperature.

5. The highest abrasion resistance was that of moxtar specimens of $20 \%$ fine lead slag.

6. The presence of fine lead slag enhanced the abrasion resistance of plain mortar and the rate of enhancement is more pronounced at temperatures above $5000 \mathrm{C}$.

\section{REFEREIUCES}

[1] Jepsen, M. T., Mathiesen, D., Munch-Petersen, C., Bager, D., (2001), Durability of resource saving "Green" type of concrere, In: Proceedings of FIB - Symposium on concrete and environment, Berlin.

[2] Monce, N. and Ashfaq, K., (2001), Cementitious composites containing recycled tire rubber: an overview of engineering properties and potentia? applications, Cement Concrete Aggregate, Vol. 23, pp. 3-10.

[3] Basri, H. B., Mannan, M. A., Zain, M. F. M., (1999), Concrate using waste oil palm shells as aggregate, Cement Concrete Research, Vol. 29, pp. 619-22.

[4] Padmini, A. K, Ramamurthy, K., Mathews, M. S., (2001), Behaviour of concrete with low-strength bricks as lightweight coarse aggregate, Magazine of Concrete Research, Vol. 53, pp. 367-375.

[5] Palmquist, S. M., Jansen, D. C., Swan, C. W., (2001), Compressive behavior of concrete with vitrified soil aggregate, ASCE J. Mater. Civil Eng., Vol. 13, pp. 389-394.

[6] Binici, H., (2007), Effect of crushed ceramic and basaltic pumice as fine aggregates on concrete mortars properties, Construction and Building Materials, Vol. 21, pp. 119i-119\%.

[7] De Brito, J., Pereira, A. S., Correia, J. R. (2005), Mechanical behaviour of non-structural concrete made with recycled ceramic aggregates, Cement \& Concrete Composites, Vol. 27, pp. 429-433.

[8] Metwally, M. E. A, Seleem, M. H., Balaha, M. M., and Abd El-Rahman, H. (2005), Utilization of slag produced from recycling of spent lead-batteries as concrete aggregate, Alexandria Engineering Journal, Vol. 44, pp. 883-892.

[9] Penpolcharoen, M. (2005) Utilization of secondary lead slag as construction material, Cement and Concrete Research, Vol. 35, pp. 1050-1055

[10] Bilirb, İ. Y. T, and Özkanc, Ö., (2007), Durability of concrete incorporating non-ground blast furnace slag and bottom ash as tine aggregate . Building and Environment, Vol. 42, pp. 26512659.

[11] American Society for Testing and Materials, (1989) "Test method for abrasion resistance of horizontal concrete surfaces", ASTM C779-89, Annual Book of ASTM Standard, ASTM, 4.02, p 359.

[12] El-Shihy, A. M., Seleen, M. H., Shoaib, M. M. Badawy, A. A. M, and Gabal, A. E. K. (2004) Effect of elevated temperatures on the mechanical and physico-chemical behavior of normal, high strength and light weight concrete. Mansoura $4^{\text {th }}$ Int. Engineering Conf,. 20-22 April, C51-C59.

[13] Hewlett, P. C., (1998), Lea's chemistry of cement and concrete. Co-published in North Central and South America by Jhon Wiely \& Sons Inc., New York and Toronto, $4^{\text {th }}$ edition.

[14] Zang, B., Bicanic, N., Pearce, C. J. and Balabanis, G. (2000), Residual fracture properties of normal and high-strength concrete subjected to elevated temperature. Magazine of Concrete Research, Vol. 52, No.2, pp. 123-136.

[15] Wei-Ming Lin, Lin, T. D. and Powers-Couche, (1996), Microstructures of fire-damaged concrete. ACI, Material Journal, Vol. 93, No. 1, pp. 199-205.

[16] Chan, S. Y. N. Peng, G. F., Anson, M., (1999) Residual strength and porestructure of highstrength concrete and normal-strength concrete after exposure to high temperatures, Cement \&. Concrete. Composite, Vol. 21, pp. 23-27. 


\title{
EFFECT OF HIGH TEMPERATURE ON THE MECHANICAL STRENGTH OF RUBBERIZED CONCRETE MORTAR
}

\author{
M. H. Seleem, M. M. Balaha, H. S. Khalil, E. Zaki \\ Engineering Materials Department, Faculty of Engineering, Zagazig University, Egypt
}

\begin{abstract}
The development of environmentally accepted metbods of used tire disposal is one of the greatest challenges that waste management experts face today. When building materials are subjected to fire and exposed to cooling, some changes may occur in their characteristics; such as phase transformation, weight loss, aggregate-cement bond, etc., which directly affects on its chemical stability and mechanical properties. In the present investigation, the effect of high temperature of the compressive and tensile strengths of concrete mortar fabricated from ground waste tire rubber (GWTR) as a partial replacement of total fine aggregate (TFA), sand, was experimentally investigated. The percentages by volume of GWTR/TFA were, $0 \%, 5 \%, 10 \%, 15 \%$ and $20 \%$. All mortar samples were prepared and cured using tap water for 28 days, then kept in laboratory atmosphere until the beginning of the test. The specimens were subjected to different target: temperatures of $100,200,300,400$ and $500^{\circ} \mathrm{C}$. After reaching to the desired target temperature, the specimens were sustained at desired temperature for 2 hours. After heating the specimens were allowed to cool at room temperature until the date of the test. The test results showed that all mortar specimens exposed to high temperature suffered a significant decrease in both compressive and tensile strengths. Replacing sand by $5 \% 10 \%$ GWTR recorded the highest relative compressive strength, while replacing sand by 10-15\% GWTR recorded the highest relative tensile strength compared with other replacement ratios. The mass loss increased with increasing of temperature up to $500^{\circ} \mathrm{C}$ and GWTR \%. In addition, at high temperature $500^{\circ} \mathrm{C}$ it was noticed that no cracks appeared on the surface of specimens.
\end{abstract}

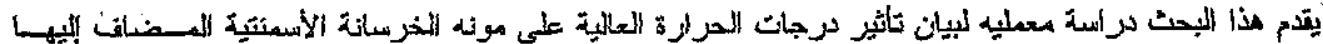

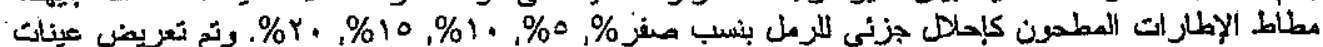

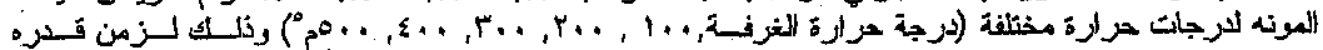

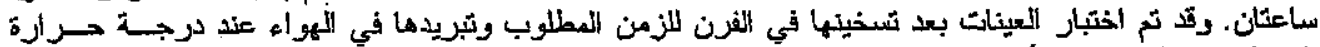

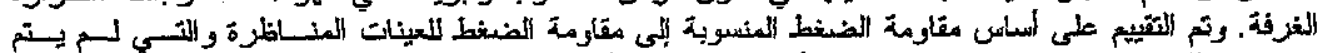

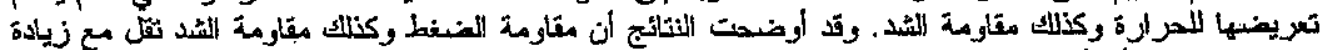

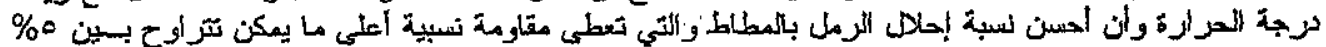

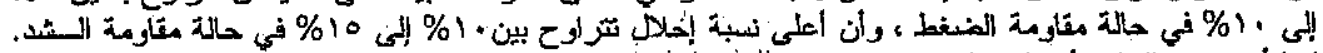

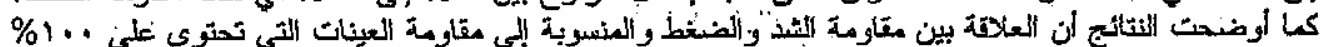

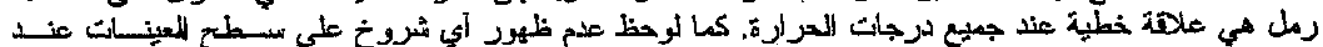

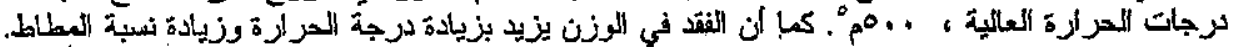

Keywords: Ground tire rubber; Mortar; High Temperature; Compressive strength; Tensile strength.

\section{INTRODUCTION}

Waste tires pose a health hazard since tire piles are excellent breeding grounds for mosquitoes. Because of the shape and impermeability of tires, they may hold water for long periods providing sites for mosquito larvae development. Waste tires also pose a serious fire hazard since wáste tires and waste tire stockpiles are difficult to ignite. However, once ignited tires burn very hot and are very difficult to extinguish. A large tire fire can smolder for several weeks or even months, sometimes with dramatic effect on the surrounding environment. An end-oflife tire is a used tire that cannot or is not reused for its originally intended purpose and is not retreated. Such tires may have a further use as a raw material for other processes or be destined for final disposal. End-of-life tires are called "scrap tires" in the United States [1]. However, all of the recycling re-uses and recovery practices combined only consume about $22 \%$ of the discarded tires. Thus, a need still exists for the development of additional uses for scrap tires $[2-4]$. Nowadays, waste tire disposal is a significant 
problem and finding an environment friendly and potentially attractive method is the greatest challenge. The difficulty in the recycling of the waste tire is that the tire rubber is a cross linked polymer that is hard to melt and to process [5-6].

Utilization of waste tires would eliminate castle pollution that is required to prevent degradation of air, land and water in the vicinity of the waste disposal sites. Also buming the remains tires rubber for getting rid of them causes a very big pollution to the environrnent. Therefore, many studies [7-9] were directed to avoid the problems due to burn the remains tires rubber and studying the role of utilization the ground waste tires rubber as aggregates in concrete. Many properties of the concrete can be improved being used the tire chips in c.ivil engineering applications such as low material density, high bulk permeability, high thermal insulation, high durability: and high bulk compressibility. On heating, a neat Portland cement paste first expands owing to its normal thermal expansion. This expansion, however, is exposed to a contraction due to the shrinkage of the material as water is driven off from it. The contraction due to drying eventually becomes much larger than its normal thermal expansion and the material then begins to shrink. The temperature at which the maximum shrinkage is reached varies with the size of the specimen and the conditions of heating. It may be as high as $300^{\circ} \mathrm{C}$ for air-dry specimens under conditions of fairly rapid heating. At more temperatures the neat cement steadily shrinks, the contraction from the original dimensions amounting ultimately about 0.5 percent or more. During this process, severe cracking occurs [10]. Hydrated Portiand cement contains a considerable proportion of free calcium hydroxide, which loses its water above $400-500^{\circ} \mathrm{C}$, leaving calcium oxide (quick lime). If $\mathrm{CaO}$ becomes wetted after cooling as exposed to moist air, it rehydrates to $\mathrm{Ca}(\mathrm{OH})_{2}$ accompanied by an expansion in volume that may disrupt a concrete, which has withstood a fire without disintegration [11].

The best fire resistant aggregate, which is characterized by a very fine crystalline texture or a non-crystalline basic material such as limestone, expands steadily until a temperature of about $900^{\circ} \mathrm{C}$ is reached, then begins to contract owing to decomposition of $\mathrm{CaCO}_{3}$ with liberation of $\mathrm{CO}_{2}$. It has often been considered, on account of this decomposition, that the concrete with limestone has no fire resistance beyond this temperature [12]. Long series of tests on the fire resistance of structures have been carried out in Britain and USA. All concretes, which are considered the most fire resistant, attained a serious reduction in strength at a temperature above $600^{\circ} \mathrm{C}$ and fail if exposed for a considerable time to a temperature exceeding $900^{\circ} \mathrm{C}$ [13]. However, regardless the different nature, size and composition of used tire rubbers, a meaningful decrease in concrete compressive strength with the increasing amount of rubber phase in the mixture was always detected [14]. It was found that the damping ratio of rubberized concrete containing $20 \%$ rubber is much higher than that of traditional concrete by about $63.2 \%$

In the present investigation ground waste tires rubber was used as a partial replacement for fine aggregates by volume $(0 \%, 5 \%, 10 \%, 15 \%$ and $20 \%)$. All mortars samples were exposed to five different temperatures $100,200,300,400$ and $500^{\circ} \mathrm{C}$ for 2 hours soaking time with heating rate of $10-20^{\circ} \mathrm{C}$. The weight loss and residual compressive and tensile strengths due to exposure to those high temperatures were experimentally investigated in the present paper.

\section{EXPERIMENTAL PROGRAMME}

The cement used in mortar mixes was ordinary Portland cement (OPC) from Suez Cement Company. The properties of the used cement are given in Table 1. The used sand was siliceous sand with $100 \%$ passing ASTM sieve No. 4 with a fineness modulus of 2.75 . The cement content was $400 \mathrm{~kg} / \mathrm{m}^{3}$. The sand to cement ratio was equal to $3: 1$. The used ground waste tire rubber (GWTR) in this research was produced by (El-Nasr Tire Company) by grinding the waste tires with special technique. The total fine aggregates (TFA) in all mixes were sand partially replaced by fine GWT'R particles. The percentages by volume of GWTR/TFA were $0 \%, 5 \%$, $10 \%, 15 \%$ and $20 \%$. Sieve analysis of the used GWTR and sand are given in Table 2: The physical properties of the used fine GWTR are given in Table 3. Cubes $70 \times 70 \times 70 \mathrm{mms}$ were prepared for testing under static compressive loadings. Cylinders of $75 \mathrm{mms}$ diameter and $150 \mathrm{mms}$ height were prepared for testing under indirect tension test. The mortar constituent materials were batched separately by weight. Mixing was performed in a small rotatingdrum mixer. First, cement and waste tire nbber were dry mixed until a homogeneous mix was observed before mixing the sand to it, and then water was gradually added while mixing continued for about five minutes. All specimens were cast in steel molds, then demolded after 24 hours ancl cured in fresh water for 28 days. All specimens were cast and treated under the same environmental conditions.

After curing, the specimens were exposed to temperatures of $100,200,300,400$ and $500^{\circ} \mathrm{C}$ and kept at that temperature for 2 hours in semi-open muffle furnace with an average heating rate of $10^{\circ} \mathrm{C}$ per minute. After heating, the specimens were left to cool in air until the time of testing. The compressive 
and indirect tensile tests were carried out in a hydraulic universal testing machine of $1000 \mathrm{kN}$ capacity.

Table 1 Properties of the used OPC

\begin{tabular}{|l|c|c|}
\hline \multicolumn{1}{|c|}{ Property } & Results & $\begin{array}{c}\text { B.S. } \\
\text { Limits }\end{array}$ \\
\hline Initial setting time & $1.45 \mathrm{hr}$ & $\geq 45 \mathrm{~min}$ \\
\hline Final setting time & $4.25 \mathrm{hr}$ & $\leq 10 \mathrm{hr}$ \\
\hline Fineness, $\mu \mathrm{m}$ & 8 & $\leq 10$ \\
\hline Compressive strength & & \\
$\left(\mathrm{kg} / \mathrm{cm}^{2}\right)$ & & \\
After 3 days & 225 & $\geq 160$ \\
After 7 days & 297 & $\geq 240$ \\
After 28 days & 379 & $\geq 360$ \\
\hline
\end{tabular}

Table 2 Sieve analysis of GWTR and sand.

\begin{tabular}{|c|c|c|}
\hline \multirow{2}{*}{ Sieve Opening, mm } & \multicolumn{2}{|c|}{ \% passing } \\
\cline { 2 - 3 } & GWTR & Sand \\
\hline 5 & 100 & 100 \\
\hline 2.5 & 100 & 97.8 \\
\hline 1.25 & 13.4 & 84.9 \\
\hline 0.62 & 3.8 & 58.4 \\
\hline 0.31 & 1.6 & 8 \\
\hline 0.16 & 0.6 & 2.2 \\
\hline
\end{tabular}

Table 3 Physical properties of GWTR.

\begin{tabular}{|l|c|c|}
\hline \multicolumn{1}{|c|}{ Property } & GWTR & Sand \\
\hline Specific gravity & 0.9 & 2.45 \\
\hline Unit weight g/cm & 0.67 & 1.7 \\
\hline Absorption \% & 1.9 & 0.42 \\
\hline Fineness Modulus & 3.81 & 2.45 \\
\hline
\end{tabular}

\section{RESULTS AND DISCUSSIONS}

\subsection{Compressive Strength}

The effect of high temperatures on the relative compressive strength of mortar specimens fabricated by partial replacement of sand by GWTR (GWTR/TFA \% $=0,5,10,15$ and $20 \%$ ) is shown in Fig. 1. The relative compressive strength showed in the figure is ratio multiplied by 100 of the strength of specimen exposed to high temperature to that of the unheated specimen at the same GWTR/TFA \%. It is clear that, all mortar mixes exposed to fire suffered a significant depression in compressive strength.

The average relative compressive strength for all GWTR/TFA \% was about $93,90,83,75$ and $56 \%$ for target temperatures of respectively $100,200,300$, 400 and $500^{\circ} \mathrm{C}$. The small gradual decrease in the compressive strength at low temperature may be due to the existence of rubber particles absorbs the volume change occurred in the specimens due to heating. At high temperature $\left(500^{\circ} \mathrm{C}\right)$, higher reduction in compressive strength is observed and this may be due to melting of the rubber particles and increasing porosity in the mortar specimens. Thermal decomposition of some binding products such as $\mathrm{Ca}-$ sulphate- aluminate hydrate and calcium silicate hydrates may also the reasons for the higher reduction in the compressive strength at high temperatures.

Figure 2 demonstrates the effect of GWTR \% on the relative compressive strength of mortar specimens at different high temperatures. The figure clearly indicates that the relative compressive strength increases with increasing GWTR up to $5 \%$ at some temperature and $10 \%$ others and after that it decreases at all temperatures. Thus we can conclude that the optimum GWTR \% for high temperatures applications under compression loads is ranged from $5 \%$ to $10 \%$.

To explain the effect of GWTR/TFA \% on the compressive strength of mortar, the strength of specimen exposed to high temperature and containing GWTR was divided by that of $100 \%$ sand and exposed to the same target temperature. This is defined as the compressive strength ratio. The effect of GWTR/TFA $\%$ on the strength ratio at different exposure temperature including room temperature is shown in Fig. 3. The same trend for all target temperature is observed, i.e. linear reduction in the strength ratio with increasing GWTR/TFA \%.

The data in the data figure best fit the following relation between the GWTR/TFA \% and the compressive strength ratio:

Strength ratio, $\%=100-2.13$ (GWTR/TFA \%)

At GWTR/TFA \% equal to zero, the compressive strength is the strength of $100 \%$ sand specimens. The above equation is valid up to GWTR/TFA \% equal to $46.95 \%$.

\subsection{Tensile Strength}

The tensile strength of GWTR mortar specimens shows similar trends as that of compression. The effect of high temperatures on the relative tensile strength of mortar specimens fabricated by partial replacement of sand by GWTR (GWTR/TFA $\%=0$, $5,10,15$ and $20 \%$ ) is shown in Fig. 4. The relative tensile strength showed in the figure is ratio multiplied by 100 of the strength of specimen exposed to high temperature to that of the unheated specimen at the same GWTR/TFA \%. It is clear that, all mortar mixes exposed to fire suffered a gradual decrease in the relative tensile strength with increasing high temperatures. 
M. Seleem, M. Balaha, H. Khalil, E. Zaki, "Effect of High Temperature on the Mechanical Strength of ..."
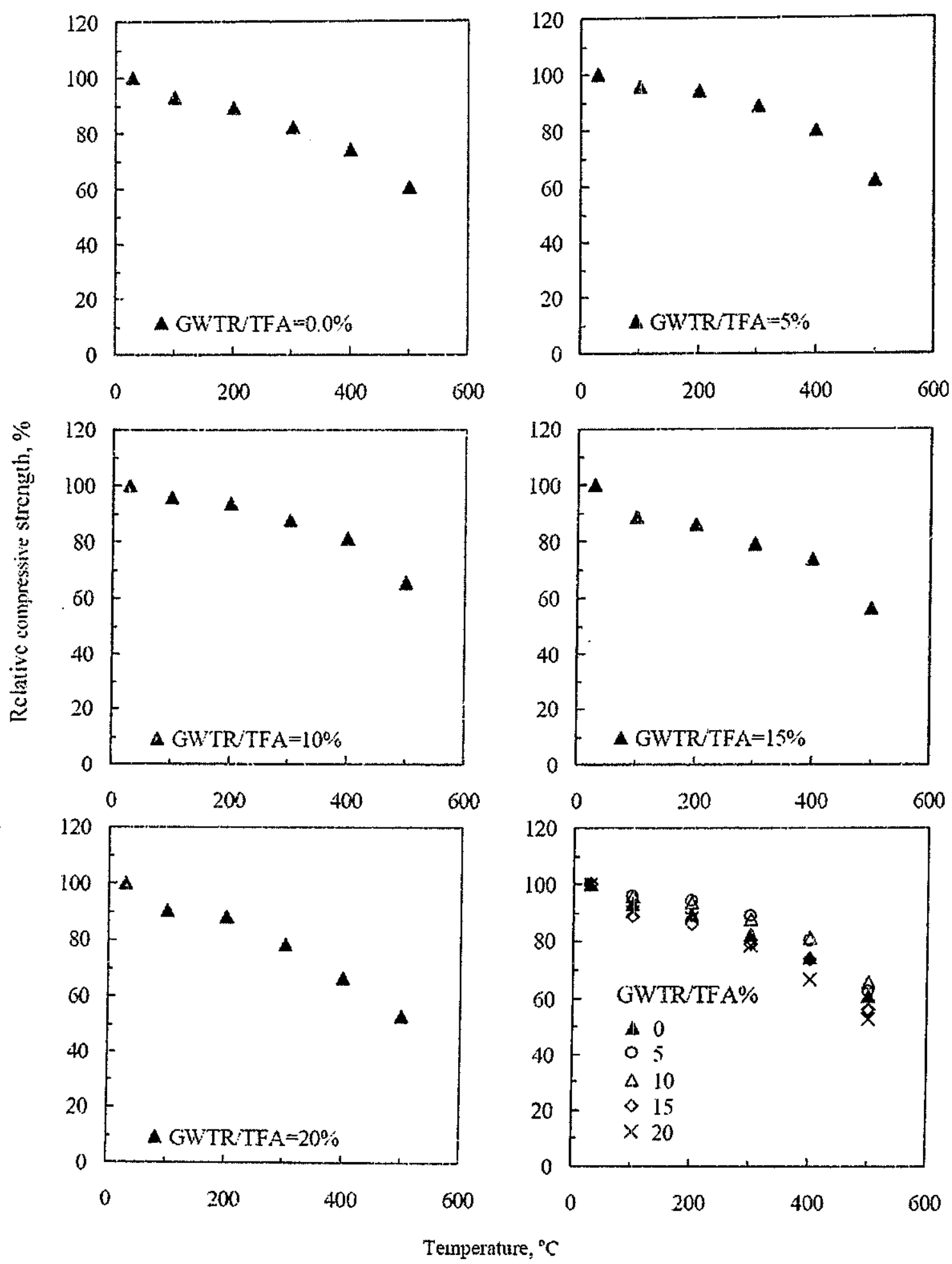

Fig. 1 Relative compressive strength against temperatures for different GWTR/TFA \%. 
The average relative strength for all GWTR/TFA \% was about $97,94,86.5,81.5$ and $64 \%$ for target temperatures of respectively $100,200,300,400$ and $500^{\circ} \mathrm{C}$. These average relative strengths are higher to some extent to those recorded under compression. This means that the degradation in the strength in the case of tensile stresses is smaller than that in the case of compressive stresses. This is expected due to the small resistance of rubber particles to compression load compared to its better resistance to tensile loads. The small gradual decrease in the tensile strength at low temperature may be due to the existence of rubber particles absorbs the volume change occurred in the specimens due to heating. At high temperature $\left(500^{\circ} \mathrm{C}\right)$, higher reduction in the tensile strength is observed and this may be due to melting of the rubber particles and increasing porosity in the mortar specimens. Thermal decomposition of some binding products such as $\mathrm{Ca}$-sulphate- aluminate hydrate and calcium silicate hydrates may also the reasons for the higher reduction in the tensile strength at high temperatures. Visual examination of specimen surfaces of GWTR mortar after exposure to high temperatures up to $\left(500^{\circ} \mathrm{C}\right)$ reveals no cracks appeared on such surface. This indicates that the presence of GWTR absorbed any volume changes in the matrix as a result of thermal expansion.

Figure 5 demonstrates the effect of GWTR \% on the relative tensile strength of mortar specimens at different high temperatures. The figure clearly indicates that the relative tensile strength increases with increasing GWTR up to $10 \%$ in some cases and up to $15 \%$ in other cases and after that it decreases at all temperatures. Thus we can conclude that the optimum GWTR \% for high temperatures applications under tensile loads is ranged between $10 \%$ and $15 \%$.

To explain the effect of GWTR/TFA \% on the tensile strength of mortar, the strength of specimen exposed to high temperature and containing GWTR was divided by that of $100 \%$ sand and exposed to the same target temperature. This is defined as the tensile strength ratio. The effect of GWTR/TFA \% on the tensile strength ratio at different exposure temperature including room temperature is shown in Fig. 6. The same trend for all target temperature is observed, i.e. linear reduction in the tensile strength ratio with increasing GWTR/TFA \%. The data in the data figure best fit the same relation in compression between the GWTR/TFA \% and the tensile strength ratio.

\subsection{Mass loss}

Heat induced mass losses due to water evaporation and melt of rubber for all mixtures are shown in Fig. 7. The mass loss illustrated in this figure represents the normalization of the difference in mass loss between the unheated and heated specimens to that of the unheated specimens multiplied by 100 . All mixtures demonstrated an increase in the mass loss percentage with increasing tempreture. These losses are increased with increasing GWTR to high temperature. The loss rate is low at the first stages of heating up to tempreature of $200^{\circ} \mathrm{C}$. When the heating temperature is under $200^{\circ} \mathrm{C}$, the mass loss is completely caused by quick evaporation of capillary water, and concrete undergoes a physical process. For a temperature between 200 and $400^{\circ} \mathrm{C}$, the weight loss is mainly caused by gradual evaporation of gel water and melt of rubber, and the concrete undergoes a mix physico-chemical process. For a temperature over $400^{\circ} \mathrm{C}$, the weight loss is mainly caused by the melt of rubber and evaporation of chemically combined water (dehydration) and decomposition, so the concrete undergoes a chemical process [10].

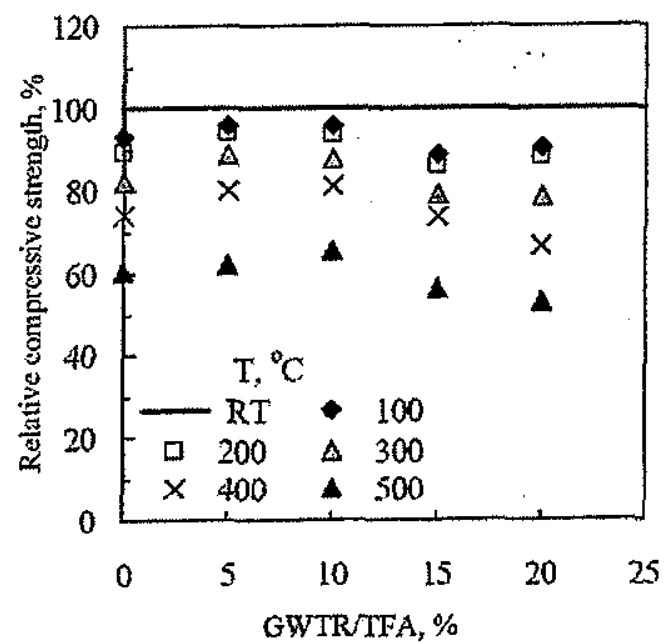

Fig.2 Effect of GWTR \% on the relative compressive strength

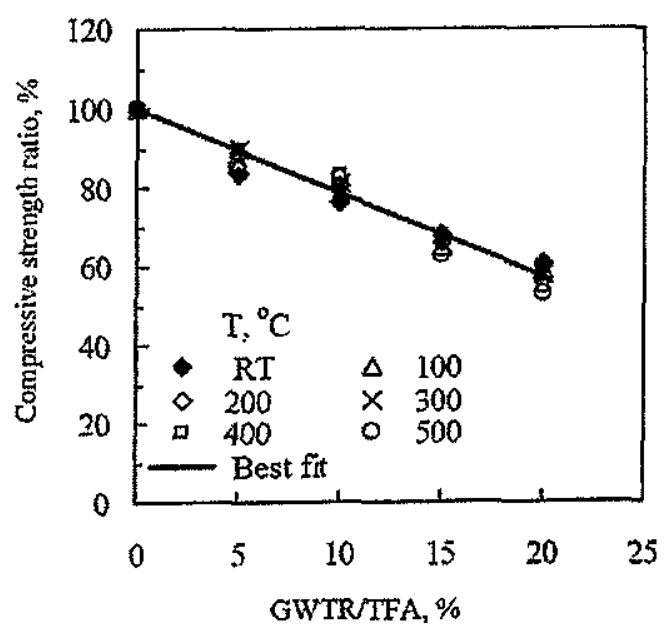

Fig. 3 Effect of GWTR \% on the compressive strength ratio 
M. Seleem, M. Balaha, H. Khalil, E. Zaki, "Effect of High Temperature on the Mechanical Strength of ..."
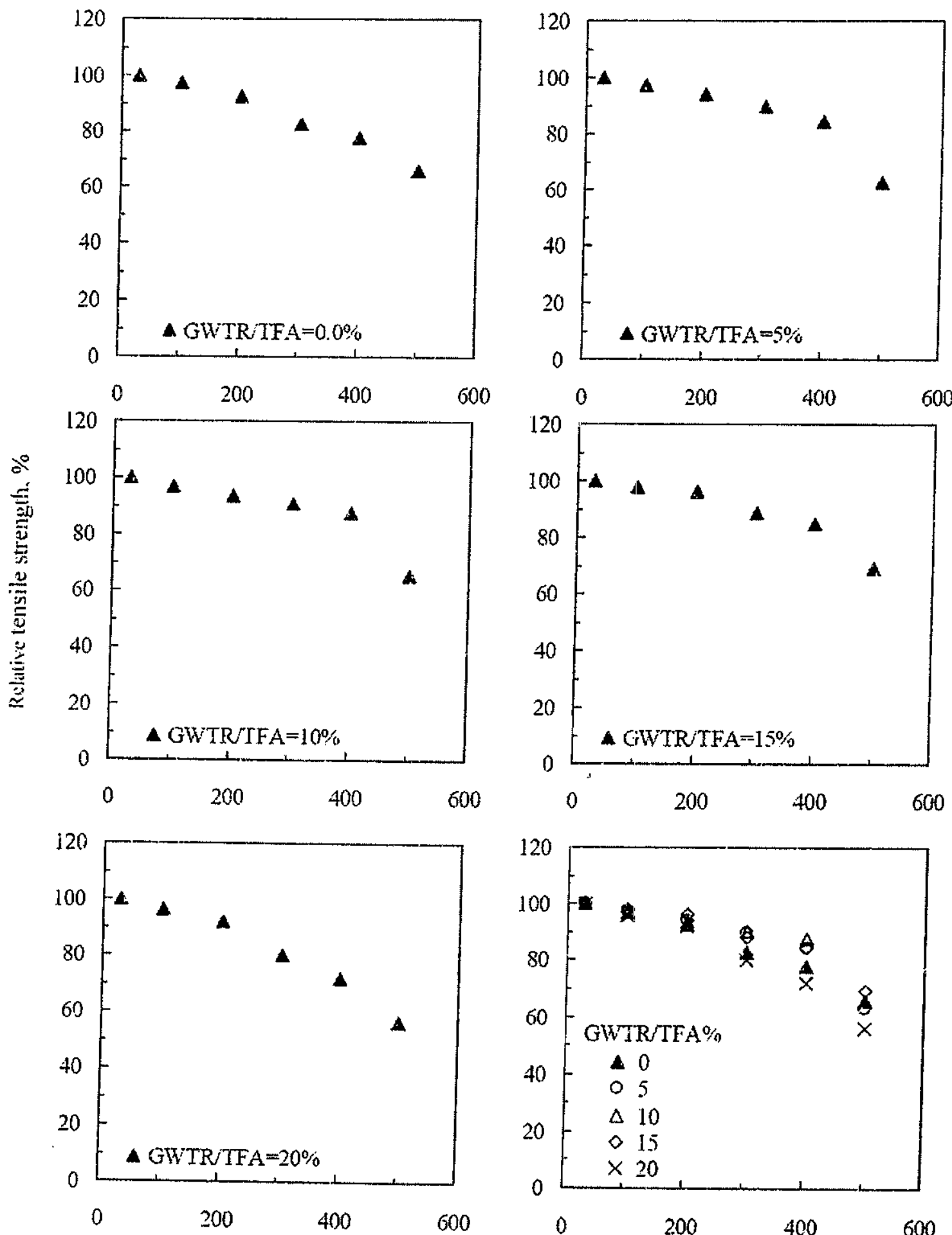

Tenperature, ${ }^{\circ} \mathrm{C}$

Fig. 4 Relative tensile strength against temperatures for different GWTR/TFA \%. 


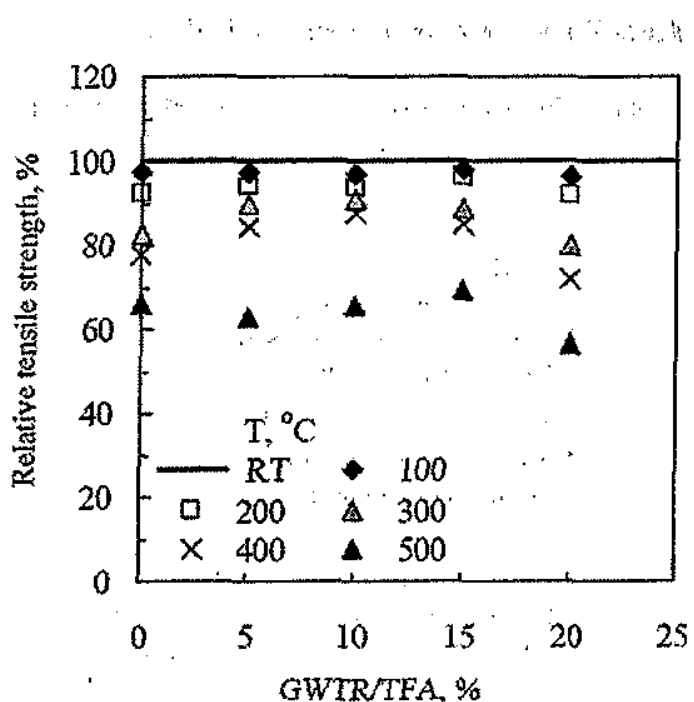

Fig.5 Effect of GWTR \% on the relative tensile strength

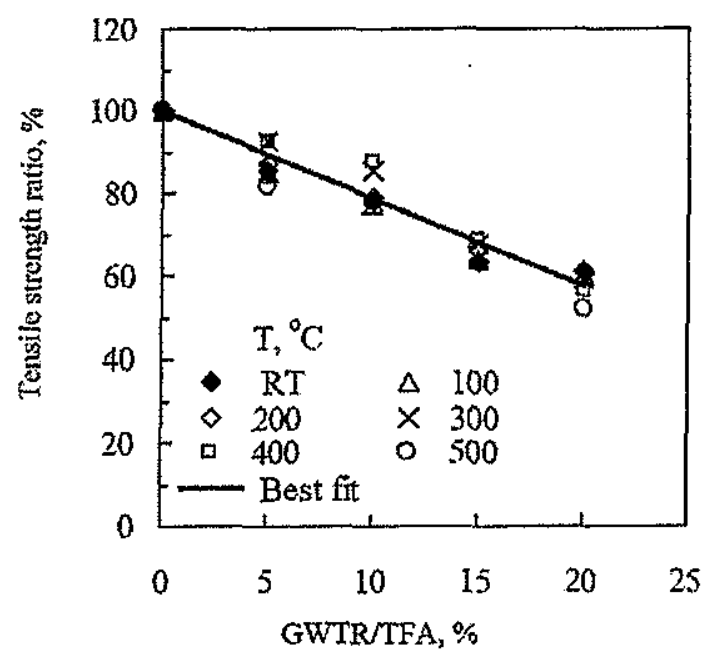

Fig.6 Effect of GWTR \% on the tensile strength ratio

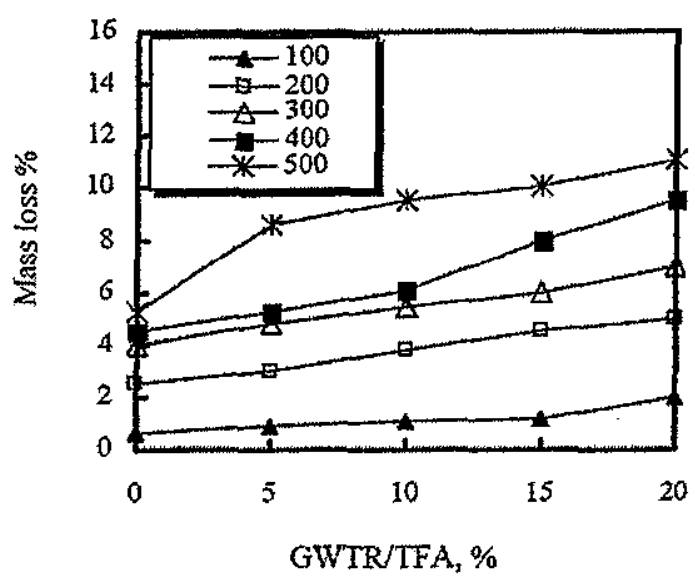

Fig.7 Effect of GWTR \% on mass loss percentage.

\section{CONCLUSIONS}

Based or 'the test results from this study the following conclusions could be drawn as follows:

1- All mortars specimens exposed to high temperatures showed a decrease in both compressive and tensile strengths with increasing temperature. The reduction in the compressive strength was higher than that recorded in tensile strength.

2- The GWTR/TFA \% showed remarkable effect on the mortars compressive and tensile strengths after their exposure to high temperature. Where, the compressive strength and tensile strengths of rubberized mortars decreased with increasing of GWTR/TFA \%.

3- The optimum GWTR $\%$, which gave the highest relative compressive strength, was in the range from $5 \%$ to $10 \%$, while that gave the highest relative tensile strength was in the range from $10 \%$ to $15 \%$.

4- A linear relation existed between the compressive strength ratio and the tensile strength ratio (ratio of the strength of rubberized mortar to that of $100 \%$ sand at specified temperature) and the GWTR \% at all temperatures considered.

5- The mass loss increased with increasing of temperature up to $5000 \mathrm{C}$ and GWTR $\%$.

\section{REFERENCES}

[1] Jang, J. w., T. Oh, J, and Iwasaki, I., (1998) "Discarded Tire Recycling Practices in the United States, Japan and Korea. Resources", Conservation and Recycling Vol. 22, pp. 1-14.

[2] Garrick G. M, (2005), "Analysis and Testing of Waste Tire Fiber Modified Concrete", M. Sc., Jamaica, Mechanical Engineering Dept., Louisiana State University.

[3] Cecich V, Gonzales L, Hoisaeter A, Williams J \& Reddy K R, (1994), Use of Shredded Tyres as a Lightweight Backfill Material for Retaining Structures, Report No. CE-GEE-94- 02, University of Illinois at Chicago, Chicago, Illinois, U.S.A.

[4] Humphrey D. N., Sandford, T. C., Cribbs, M. M. \& Manion, W. P., (1993), Shear Strength and Compressibility of Tire Chips for Use as Retaining Wall Backfill, Transportation Research Record 1422, Washington D.C., U.S.A.

[5] Jang J. W., Yoo T., Oh J. \& Iwasaki I., (1998) Japan-Korea. Resources, Conserv Recycle, Vol. 22, pp. 1-14. 
[6] Biel T. D. \& Lee H., (1994), Use of Recycled Tire Rubbers in Concrete, Proc ASCE $3^{\text {rd }}$ Materiais Engineering Conf, Infrastructure: New Materials and Methods of Repair, pp. 351-358.

[7] Humphrey, D. N., Eaton, R. A., (1993), Tire Chips as Subgrade Insulation-Field Trial, Symposium on Recovery and Effective Reuse of Discarded Materials and By-Products for Construction of Highway Facilities, Denver, Colorado, U.S.A.

[8] Upton, R. J., Machan, G., (1993), Use of Shredded Tires for Lightweight Fill, Transportation Research Record 1422, Washington, D.C., U.S.A.

[9] Humphrey, D. N., (1999), Civil Engineering Applications of Tire Shreds, Proc Tire Industry Conf, Clemson University, March 3-5, p 16.

[10] Lea, F. M., (1998), The Chemistry of Cement and Concrete, $4^{\text {th }}$ Edn, Arnold Pub. Group, London.
[11] Ramachandran, V. C., (1969), Application of Differential 'Themal Analysis in Cement Chemistry, Chemical Publishing Company, INC., New York.

[12] British Standard Institution, (1990), Specification for Light Weight Aggregate for Masonry Ünits and Structural Concrete, B.S. 3793, London, 1990.

[13] František škvàra and Vàclav ševèik, (1999) Influence of High Temperature on GF Portland Cement Materials, Cem Concr Res 29, pp. 713717.

[14] Balaha, M. M., Badawy, A. A. M and Hashish, M., (2007), "Effect of using ground waste tire rubber as fine aggregate on the behavior of concrete mixes", Indian Journal of Engineering \& Materials Sciences Vol. 14, December 2007, pp. $427-435$ 


\title{
EFFECT OF MOUTHPIECE LENGTH AND POSITION ON THE DISCHARGE COEFFICIENT
}

\author{
Sayed E. A. Mahgoub \\ Hydraulics Research Institute, \\ The National Water Research Center
}

\begin{abstract}
This research investigates experimentally the different lengths, positions and direction of mouthpieces to determine the value of the corresponding discharge coefficient $\left(C_{d}\right)$ in order to specify the orifice characteristics that can be properly implemented in the field of irrigation. The experiments were carried out in the Hydraulic Research Institute in a two sided glass flume $(40 \mathrm{~m}$ long, $0.4 \mathrm{~m}$ wide and $0.6 \mathrm{~m}$ deep). 126 runs were executed during which the length and position of the mouthpiece were varied. The tested lengths, with respect to the orifice diameter, were $0.5 \mathrm{~d}$, $1 \mathrm{~d}, 1.5 \mathrm{~d}, 2 \mathrm{~d}, 3 \mathrm{~d}, 4 \mathrm{~d}$ and $5 \mathrm{~d}$, while the tested positions of mouthpieces were fitted either internally (opposite to the flow direction) or externally (along the flow direction). Supplementary tests (36 tests) were carried out for determining the discharge coefficient of the orifice (without mouthpieces) to act as a reference to the results using mouthpieces. The discharge was varied from 5 to $13 \mathrm{l} / \mathrm{s}$ with increment of $1 \mathrm{l} / \mathrm{s}$. Measurements were carried out using point gauges, ultrasonic flow-meter, current meters and a digital camera to monitor the flow inside and outside the tested mouthpieces.

The results were analyzed and represented. The results revealed that increasing the throat length results in decreasing the loss coefficient to a certain limit after which " $\mathrm{C}_{\mathrm{d}}$ " becomes constant. Also, the results proved that the discharge coefficient in the case of an internal mouthpiece is less than that of the case of an external mouthpiece as the separation increases. It was also found that lowering the mouthipiece under the free surface causes the increase in the head $(H)$ which produces more losses.

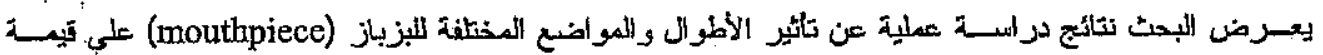

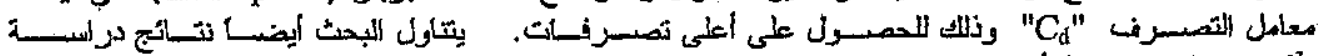

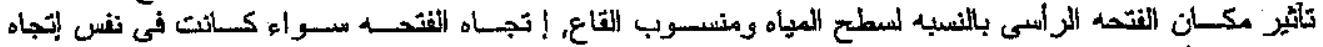

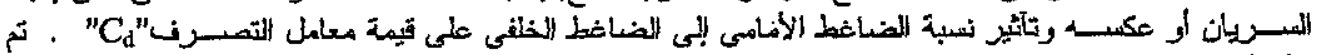

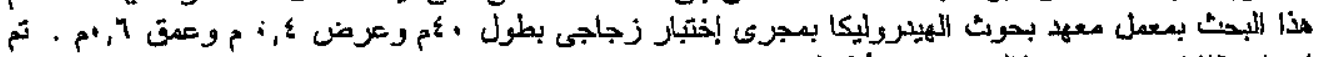

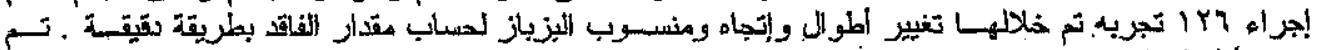

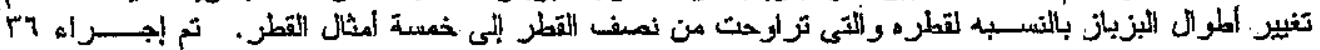

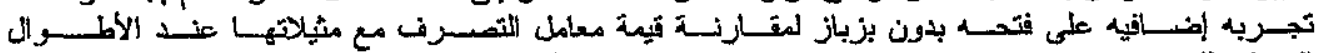

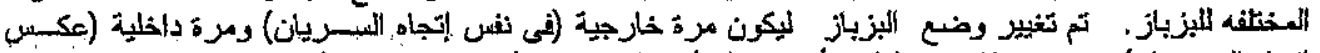

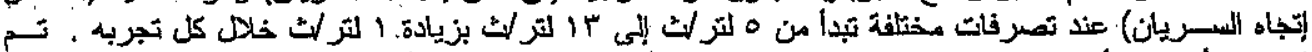

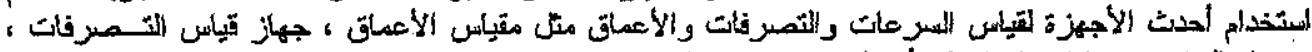

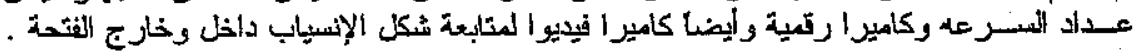

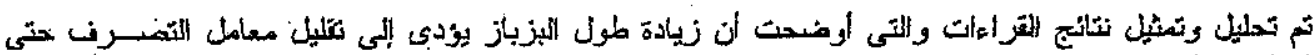

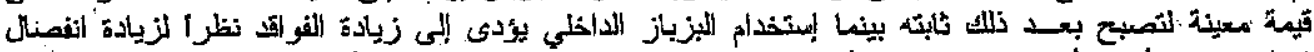

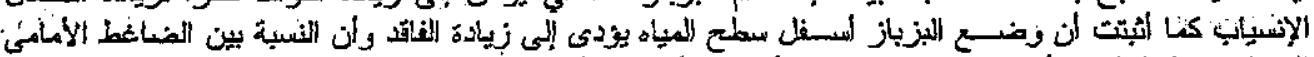

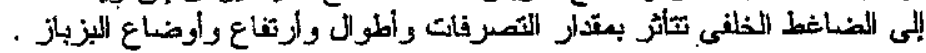

Keywords: Mouthpiece, Discharge Coefficient, Physical Model, Calibration, Separation, Losses. 